\title{
Transcellular migration of neutrophil granulocytes through the blood-cerebrospinal fluid barrier after infection with Streptococcus suis
}

Corinna Wewer ${ }^{1,2}$, Annette Seibt ${ }^{1}$, Hartwig Wolburg ${ }^{3}$, Lilo Greune ${ }^{4}$, M Alexander Schmidt ${ }^{4}$, Jürgen Berger ${ }^{5}$, Hans-Joachim Galla ${ }^{6}$, Ulrike Quitsch ${ }^{7}$, Christian Schwerk ${ }^{7}$, Horst Schroten ${ }^{7}$ and Tobias Tenenbaum ${ }^{7 *}$

\begin{abstract}
Background: A critical point during the course of bacterial meningitis is the excessive influx of polymorphnuclear neutrophils (PMNs) from the blood into the brain. Both paracellular and transcellular routes of leukocyte transmigration through the blood-brain barrier have been described in CNS diseases so far. Thus, we investigated the mechanism of PMN transmigration through the blood-CSF barrier under inflammatory conditions.

Methods: In an "inverted" Transwell culture model of the blood-CSF barrier, the zoonotic agent Streptococcus suis (S. suis) was used to stimulate porcine choroid plexus epithelial cells (PCPECS) specifically from the physiologically relevant basolateral side. Barrier function was analyzed by measuring TEER and TR-dextran-flux, and tight junction morphology was investigated by immunofluorescence. Route and mechanism of PMN transmigration were determined by immunofluorescence, electron microscopy and FACS analysis. Quantitative real time-PCR was used to determine expression levels of ICAM-1 and VCAM-1.

Results: Here, we show that the transmigration of PMNs through PCPECs was significantly higher after stimulation with TNF $\alpha$ or infection with S. suis strain 10 compared to its non-encapsulated mutant. Barrier function was not significantly affected by PMN migration alone, but in combination with S. suis infection. Tight junction and cytoskeletal actin reorganisation were also observed after stimulation with S. suis or TNF $\alpha$. Most strikingly, PMNs preferentially migrated across PCPECs via the transcellular route. Extensive sequential analyses of the PMN transmigration process with Apotome ${ }^{\circledR}$-imaging and electron microscopy revealed that paracellular migrating PMNs stop just before tight junctions. Interestingly, PMNs subsequently appeared to proceed by transcellular migration via funnel-like structures developing from the apical membrane. It is noteworthy that some PMNs contained bacteria during the transmigration process. Flow cytometric and transmigration inhibition studies with integrin-specific antibodies showed that PMN traversal is dependent on CD11b/CD18. Analysis of cell adhesion molecules in PCPECs revealed a significant increase of ICAM-1 and VCAM-1 expression after TNF $\alpha$ and S. suis stimulation.
\end{abstract}

Conclusion: Our data underline the relevance of the blood-CSF barrier as a gate for leukocyte entry into the CNS and suggest a novel transcellular migration step during the pathogenesis of bacterial meningitis.

\section{Background}

Bacterial meningitis is still an important cause of mortality and morbidity despite advances in antimicrobial therapy $[1,2]$. Especially, the exact role of the blood-cerebrospinal fluid (CSF) barrier, which is constituted by epithelial cells

\footnotetext{
* Correspondence: Tobias.Tenenbaum@umm.de

${ }^{7}$ Pediatric Infectious Diseases, Department of Pediatrics, University Hospital

Mannheim, Heidelberg University, Mannheim, Germany

Full list of author information is available at the end of the article
}

of the choroid plexus $(\mathrm{CP})$, in bacterial meningitis is under investigation $[3,4]$. Important functions of the $\mathrm{CP}$ are maintaining homeostasis in the CNS, CSF secretion and participation in neurohumoral brain modulation and neuroimmune interaction $[5,6]$.

Streptococcus suis (S. suis) is a swine and emerging human pathogen causing a wide range of infections like meningitis and septicaemia [7]. S. suis has been suggested to enter the brain via the blood-CSF barrier. In fact,

\section{Ciomed Central}

(C) 2011 Wewer et al; licensee BioMed Central Ltd. This is an Open Access article distributed under the terms of the Creative Commons Attribution License (http://creativecommons.org/licenses/by/2.0), which permits unrestricted use, distribution, and reproduction in any medium, provided the original work is properly cited. 
lesions have been observed at the CP in natural and experimentally induced cases of $S$. suis meningitis in pigs and mice [8-10]. In an inverted Transwell filter model of primary porcine CP epithelial cells (PCPECs) S. suis invades PCPECs specifically from the basolateral side in a capsule-dependent manner [4]. Furthermore, after apical infection of PCPECs with S. suis, tight junction function, morphology and protein expression is significantly altered [3,11].

Inflammatory activation of epithelial and endothelial cells, e.g. after bacterial infection, induces the release of interleukin-8 (IL-8) and other chemokines that recruit polymorphnuclear neutrophils (PMNs), which transmigrate across the cellular barriers and build the first line of defence to subcellular spaces [12,13]. For endothelial cells two possible routes for leukocyte transmigration have been described: paracellular and transcellular [14,15]. Ling et al. have reported that monocytes traverse epiplexus cells by a process called emperipolesis, whereby monocytes migrate through the epithelial cells [16]. In contrast, for PMNs only data for paracellular transmigration through epithelia exist so far [12,13].

The molecular events of a transcellular pathway involve a rather complicated mechanism wherein a zipperlike model of junctional disruption is easy to envision. Many studies may undervalue the frequency of transcellular events since they appear in very close proximity to the junctions and thus might be mistaken for paracellular migration $[17,18]$. Thus, the visualization of a leukocyte migrating through endothelial cytoplasm very close to, but distinct from, the junctional area requires advanced ultrastructural technical settings.

The molecular mechanisms employed by PMNs to cross endothelia and epithelia have been intensively investigated. So far only a few molecules have been found to be involved in the transmigration across epithelial monolayers; these include the leukocyte $\alpha_{\mathrm{M}} \beta_{2}$-integrin CD11b/ CD18 and the leukocyte and epithelial integrin-associated glycoprotein CD47 [12,19]. In comparison, rolling PMNs adhere firmly to endothelium via leukocyte $\alpha_{\mathrm{L}} \beta_{2}$-integrin CD11a/CD18 (leukocyte function-associated antigen-1, LFA-1) and CD11b/CD18, which bind to adhesion molecules such as intercellular adhesion molecule-1 (ICAM-1) [20].

As the CP epithelium is a potential entry point for PMNs during bacterial meningitis, we here analyzed the transmigration process of PMNs through PCPEC monolayers after infection with $S$. suis. Analyzing the traversal route of PMN, we found that paracellular migration stops in front of a tight junction. Strikingly, the epithelial cell layer forms funnel-like structures protruding from the apical membrane, which are regularly found adjacent to PMNs. We propose a new mechanism of PMN transmigration in epithelial cells, whereby PMNs transmigrate through these funnels to finally overcome the epithelial barrier via a final transcellular step.

\section{Methods}

\section{Bacterial strains and growth conditions}

S. suis serotype 2 virulent strain 10 and its isogenic nonencapsulated mutant strain $10 \mathrm{cps} \Delta \mathrm{EF}$, named strain 10 $\Delta$ cps in this study, were kindly provided by $\mathrm{H}$. Smith (DLO-Institute for Animal Science and Health, Lelystad, The Netherlands) [21]. Bacteria were maintained and inoculated as previously described [4]. Bacteria were washed twice in phosphate-buffered saline (PBS) ( $\mathrm{pH} 7.3)$ and adjusted to an optical density at $600 \mathrm{~nm}\left(\mathrm{OD}_{600}\right)$ of 0.65 . This stock solution had approximately $2 \times 10^{8}$ colonyforming units (CFU)/ml and was further diluted in fresh culture medium without antibiotics for the experiments.

\section{Preparation and cultivation of PCPECs on inverted Transwell filters}

Epithelial cells from porcine CP were obtained by a modified preparation basically as described previously [22]. For inverted cell cultures the cells were seeded on laminin- (Sigma, Deisenhofen, Germany) coated Transwell filters (pore diameter $3.0 \mu \mathrm{m}, 0.33 \mathrm{~cm}^{2}$; PET membrane, Falcon, BD, Le Pont De Claix, France), which were flipped over and placed in a medium-flooded 12-well plate as described recently [4].

Measurement of transepithelial electrical resistance (TEER) Confluence of PCPEC monolayers and barrier properties were documented by measuring TEER. TEER was measured using an epithelial tissue voltohmmeter $\left(\mathrm{EVOM}^{\circledR}\right.$, World Precision Instruments, Sarasota, FL, USA) and an STX-2 electrode system. PCPEC inverted cultures were used when TEER values reached more than $180 \Omega \times \mathrm{cm}^{2}$. In PMN transmigration experiments, TEER was monitored over a range of $4 \mathrm{~h}$. Resistance values of cells in medium alone were used as negative control values and stayed above $180 \Omega \times \mathrm{cm}^{2}$ during all experiments.

\section{Determination of paracellular permeability}

As an independent measure of paracellular permeability of CP epithelium monolayers, the passage of Texas Redlabelled dextran (MW 3000; Sigma, Deisenhofen, Deutschland) across cell monolayers in the basolateralto-apical direction was determined during PMN transmigration experiments. Texas Red-dextran (TR-dextran, $100 \mu \mathrm{g} / \mathrm{ml}$ ) was loaded into the upper compartment during the incubation period. At indicated time intervals samples from the lower compartment were collected and fluorescence was measured in duplicates in a Tecan Infinite M200 Multiwell reader (Tecan, Switzerland). TEER and permeability measurements were performed with the same cultures as PMN transmigration. 


\section{Isolation of PMNs}

For the PMN transmigration assays blood was taken from freshly slaughtered pigs at the abattoir. PMNs were isolated from non-coagulated citrate blood by Percoll density sedimentation according to the manufacturer's instructions (Biochrom, Berlin, Germany). Contaminating erythrocytes were lysed with $\mathrm{NH}_{4} \mathrm{Cl}$ on ice. PMNs were resuspended in culture medium at a cell density of $1 \times 10^{7} / \mathrm{ml}$. For transmigration assays PMNs were loaded with the fluorochrome 2',7'-bis-(2carboxyethyl)-5-(and-6)-carboxyfluorescein, acetomethyl ester (BCECF-AM; Molecular Probes, Eugene, OR, USA) according to the manufacturer's instructions.

\section{Stimulation of PCPECs and PMNs}

For transmigration experiments inverted PCPEC cultures were used when TEER had reached $180 \Omega \times \mathrm{cm}^{2}$. PCPECs were stimulated with either TNF $\alpha$ from the apical and basolateral side $(10 \mathrm{ng} / \mathrm{ml})$ for $24 \mathrm{~h}$ or basolaterally (blood-side) infected with S. suis strain 10 or strain 10 $\Delta$ cps [multiplicity of infection (MOI): 10] and hereafter incubated for $2 \mathrm{~h}$ at $37^{\circ} \mathrm{C}$ and $5 \% \mathrm{CO}_{2}$. After the incubation period penicillin/streptomycin $(100 \mathrm{U} / \mathrm{ml} / 100 \mu \mathrm{g} / \mathrm{ml})$ was added to the upper and lower compartment of the Transwell filter to inhibit further extracellular bacterial growth and therefore to prevent cytotoxic effects. PMN transmigration assays were performed after an additional 22 hours on the following day. In a second set of experiments we pre-incubated PMNs with S. suis strain 10 or strain $10 \Delta$ cps (MOI 10) for $1 \mathrm{~h}$ and hereafter performed with pre-stimulated PMN transepithelial migration assays in antibiotic-containing medium (to prevent further bacterial growth) as described below.

\section{PMN transepithelial migration assay}

For transepithelial migration assays BCECF-AM-loaded PMNs were added to the upper Transwell filter compartment (blood-side) of control, TNF $\alpha$ or S. suis stimulated cells in a PMNs:PCPECs ratio of 10:1. As chemoattractant IL-8 (10 ng/ml) was used in indicated samples and added to the lower Transwell filter compartment (CSF-side) 30 min before starting the transmigration experiments. After 4 hours of transmigration the Transwell filter inserts were removed and the 24-well plates were centrifuged $(5 \mathrm{~min}$, $300 \times$ g) to ensure that all PMNs are attached to the bottom of the wells. The supernatants were collected for permeability measurements. The PMNs were washed once with HBSS with $\mathrm{Ca}^{2+} / \mathrm{Mg}^{2+}$ and again centrifuged (5 min, $300 \times$ g). Transmigrated PMNs were lysed by $1 \%$ Triton $\mathrm{X}-100$ in PBS and quantified by fluorescence measurement with a Tecan $200 \mathrm{M}$ Infinite Multiwell reader (Tecan, Switzerland) in relation to an internal standard. For antibody blocking experiments BCECF-AM loaded PMNs or PCPECs were pre-incubated with antibodies as indicated for $30 \mathrm{~min}$ at room temperature or at $37^{\circ} \mathrm{C} / 5 \% \mathrm{CO}_{2}$, respectively. Hereafter, a transmigration assay was performed as described above. Antibodies specific to porcine epitopes (Table 1) were selected referring to the analyses of the "Third International Workshop on Swine Leukocyte Differentiation Antigens" [23,24]. Cross reactivity of antiCD47 has been described by Shahein et al. [25].

\section{Flow Cytometry}

Flow cytometric analyses was performed to test the specificity of antibodies, which were used in inhibition studies, and to investigate the expression patterns of PMN surface markers before and after transmigration. For this purpose, PMNs were stained with various antibodies according to manufacturer's instructions (Table 1). The PMN populations showed high and homogeneous integrin expression with regard to all tested integrins antibodies (data not shown). Integrin regulation before and after PMN transmigration was measured by analyzing the mean fluorescence intensities. To study the specific effect of IL-8, TNF $\alpha$ and S. suis and the transmigration itself on the integrin expression, two different additional analyses were performed. In the first, PMNs were analyzed that had transmigrated towards an IL- 8 gradient $(10 \mathrm{ng} / \mathrm{ml}$ in the lower compartment) through control or S. suis (MOI 10) or TNF $\alpha(10 \mathrm{ng} / \mathrm{ml})$ stimulated PCPEC. In the second, PMNs were used that had not yet transmigrated, but which were stimulated in non-tissue culture-treated 24well plates (employing 0, 6.7 or $10 \mathrm{ng} / \mathrm{ml} \mathrm{IL-8).} \mathrm{After} 4 \mathrm{~h}$ of transmigration or incubation with S. suis, TNF $\alpha$ and IL-8, the PMNs were collected and divided into tubes. After centrifugation ( $5 \mathrm{~min}, 300 \times \mathrm{g}$ ) the PMNs were incubated with the primary antibodies for $12 \mathrm{~min}$. Then the cells were washed twice with cell culture medium and incubated with the secondary antibody (goat anti mousePE) for 7 min followed by two washing steps. Flow cytometry was performed using a FACScan (Becton Dickinson, USA) with appropriately set light scatter gates.

\section{Immunofluorescence}

Confluent PCPECs were grown on inverted Transwell filters, stimulated with $S$. suis or TNF $\alpha$ and co-cultured with PMNs as described above. After $4 \mathrm{~h}$ of transmigration towards a gradient of IL-8, the cells were washed, fixed and permeabilized as described previously [3]. Subsequently, the cells were washed with PBS and incubated overnight at $4^{\circ} \mathrm{C}$ with the primary antibodies (Table 1 ) to stain the TJ proteins. On the following day the cells were washed again, incubated for $60 \mathrm{~min}$ with the secondary antibody (Alexa fluor ${ }^{\circledR} 594$ goat anti-chicken), with Phalloidin Alexa fluor ${ }^{\circledR} 660$ for staining the actin cytoskeleton and with 4'-6-diamidino-2-phenylindole dihydrochloride (DAPI) (1:25.000) for staining nuclei. PMNs were labelled with the granulocyte-monocyte marker SWC3a-FITC 
Table 1 Antibodies used for inhibition studies, flow cytometry and immunofluorescence

\begin{tabular}{|c|c|c|c|c|}
\hline Antibody & Clone & Species & Concentration & Company \\
\hline \multicolumn{5}{|l|}{ Primary antibodies } \\
\hline $\mathbf{I g G}_{1}, \kappa$ Isotype & MOPC-31C & Mouse & $\begin{array}{l}20 \mu \mathrm{g} / \mathrm{ml} \text { (inhibition) } \\
1: 10,10 \mu \mathrm{l} / \text { test (FC) }\end{array}$ & BD Pharmingen (Heidelberg, Germany) \\
\hline $\operatorname{lgG}_{2 \mathbf{b}}, \kappa$ Isotype & MPC-11 & Mouse & $\begin{array}{l}20 \mu \mathrm{g} / \mathrm{ml} \text { (inhibition) } \\
1: 10,10 \mu \mathrm{l} / \text { test (FC) }\end{array}$ & BD Pharmingen (Heidelberg, Germany) \\
\hline CD11a, $\lg G_{2 b}$ & BL2F1 & Mouse & $\begin{array}{l}20 \mu \mathrm{g} / \mathrm{ml} \text { (inhibition) } \\
1: 10,10 \mu \mathrm{l} / \text { test (FC)! }\end{array}$ & BD Pharmingen (Heidelberg, Germany) \\
\hline $\begin{array}{l}C D 11 R 3, \lg G_{1} \\
=\mathbf{C D} 1 \mathbf{b}\end{array}$ & $2 \mathrm{~F} 4 / 11$ & Mouse & $\begin{array}{l}20 \mu \mathrm{g} / \mathrm{ml} \text { (inhibition) } \\
1: 10,10 \mu \mathrm{l} / \text { test (FC) }\end{array}$ & Serotec (Oxford, UK) \\
\hline$\overline{C D 18}, \lg G_{1}$ & PNK-I & Mouse & $\begin{array}{l}20 \mu \mathrm{g} / \mathrm{ml} \text { (inhibition) } \\
1: 10,10 \mu \mathrm{l} / \text { test }(\mathrm{FC})\end{array}$ & BD Pharmingen (Heidelberg, Germany) or Serotec (Oxford, UK \\
\hline $\mathrm{CD} 47, \lg \mathrm{G}_{2 \mathrm{~b}}$ & $\mathrm{BRIC126}$ & Mouse & $\begin{array}{l}20 \mu \mathrm{g} / \mathrm{ml} \text { (inhibition) } \\
1: 10,10 \mu \mathrm{l} / \text { test (FC) }\end{array}$ & Serotec (Oxford, UK) \\
\hline CD49d, lgG & $\mathrm{HP} 2 / 1$ & Mouse & $\begin{array}{l}20 \mu \mathrm{g} / \mathrm{ml} \text { (inhibition) } \\
1: 10,10 \mu \mathrm{l} / \text { test (FC) }\end{array}$ & Serotec (Oxford, UK) \\
\hline $\mathrm{CD} 49 \mathrm{e}, \lg \mathrm{G}_{1}$ & VC5 & Mouse & $\begin{array}{l}20 \mu \mathrm{g} / \mathrm{ml} \text { (inhibition) } \\
1: 10,10 \mu \mathrm{l} / \text { test (FC) }\end{array}$ & BD Pharmingen (Heidelberg, Germany) \\
\hline Occludin & & Rabbit & $\begin{array}{l}1: 250 \text { (IF) } \\
1 \mu \mathrm{g} / \mathrm{ml}\end{array}$ & Zymed Laboratories (South San Franscisco, CA, USA) \\
\hline ZO-1 & & Rabbit & $\begin{array}{l}1: 250 \text { (IF) } \\
1 \mu \mathrm{g} / \mathrm{ml}\end{array}$ & Zymed Laboratories (South San Franscisco, CA, USA) \\
\hline SWC3a-FITC & $74-22-15$ & Mouse & $\begin{array}{l}1: 10 \text { (IF) } \\
10 \mu \mathrm{l} / \text { Test }\end{array}$ & Southern Biotech (Birmingham, AL, USA) \\
\hline \multicolumn{5}{|l|}{ Secondary antibodies } \\
\hline Alexa fluor ${ }^{\circledR} 594$ goat anti chicken & & Goat & $1: 1000$ (IF) & Molecular Probes (Eugene, OR, USA) \\
\hline Goat anti mouse-PE & & Goat & $1: 10,10 \mu \mathrm{l} /$ test $(\mathrm{FC})$ & Southern Biotech (Birmingham, AL, USA) \\
\hline
\end{tabular}

SWC: swine workshop cluster.

(1:10 in PBS) (Southern Biotech, Birmingham, AL, USA) for $30 \mathrm{~min}$. After washing the cells three times with PBS the filters were embedded in ProLongAntifadeReagent (Invitrogen, Karlsruhe, Germany). Images were acquired with Zeiss Apotome ${ }^{\circledR}$ and Axiovision software (Carl Zeiss, Jena, Germany) using a $63 \times / 1.4$ objective lens. The image acquisition was carried out using the Zeiss scanning software Axiovison 4.6 and Axiovison module Inside 4D. Assays were performed in triplicates for each value and repeated at least four times.

\section{Transmission electron microscopy (TEM)}

PCPECs were grown on inverted Transwell filters, stimulated and co-cultured with PMNs as described above. After a 4-h coincubation period, the cells were washed once with culture medium, twice with Dulbecco's-PBS and hereafter fixed with $2 \%$ glutaraldehyde (Polyscience, Warrington, PA, USA) in D-PBS, $\mathrm{pH} \mathrm{7.4,} \mathrm{for} 24 \mathrm{~h}$ at $4^{\circ} \mathrm{C}$. The Transwell filter membranes were cut out of the insert and washed three times with D-PBS and post-fixed with $1 \%$ osmiumtetroxide. After another three washes with D-PBS the samples were dehydrated by a graded ethanol series $(30 \%, 50 \%, 70 \%, 90 \%$, 96\% for 15 min each, $2 \times 99 \%$ for $30 \mathrm{~min}$ each) and two washes with propylenoxide. During the $70 \%$ ethanol step of the graded ethanol series, the specimens were incubated in saturated uranyl acetate. After completion of dehydration, the preparations were embedded in Araldite 502 (Sigma-Aldrich) at $60^{\circ} \mathrm{C}$ for $48 \mathrm{~h}$. Ultrathin sections were prepared on a Leica FCR Ultracut ultramicrotome and stained with lead citrate. Sections were examined using a Zeiss EM 10 electron microscope.

\section{Scanning electron microscopy}

Samples were fixed with $2.5 \%$ glutaraldehyde in cacodylate buffer, postfixed with $1 \%$ osmium tetroxide in phosphate-buffered saline, dehydrated in a graded series of ethanol and critical-point-dried using $\mathrm{CO}_{2}$. Finally, the samples were sputter-coated with a layer of $7 \mathrm{~nm}$ gold/ palladium (Bal-Tec MED 010) and examined at $20 \mathrm{kV}$ accelerating voltage in a Hitachi S-800 field emission scanning electron microscope.

\section{Quantitative real-time PCR}

After treatment with S. suis [strain 10 and strain $10 \mathrm{cps} \Delta \mathrm{EF}$ (short: strain $10 \Delta \mathrm{cps})]$ or TNF $\alpha(10 \mathrm{ng} / \mathrm{ml})$ for 2 and $4 \mathrm{~h}$ inverted PCPEC monolayers were washed with PBS and total cellular RNA was extracted using the RNeasy mini kit (Qiagen, Hilden, Germany) modified for inverted cell cultures. For every stimulus, three Transwell 
filters were used. Briefly, Transwell filter membranes were cut out of the insert and transferred into 48 wells. The cells on the filter membrane were lysed by resuspending them in $100 \mu \mathrm{l}$ of RLT (ready to load) buffer. Lysed cells of every triplicate were collected and filled to $350 \mu \mathrm{l}$ with RLT buffer and homogenized by QIAshredder (Qiagen, Hilden, Germany) followed by RNA extraction. Contaminating DNA was digested with the RNase-free DNase I (Roche, Mannheim, Germany) for $60 \mathrm{~min}$ at room temperature. DNase was inactivated by $1 \mathrm{~min}$ at $72^{\circ} \mathrm{C}$. After spectrophotometrical determination of the RNA concentration using a NanoDrop (Thermo Scientific, Wilmington, USA) 145 - 300 ng of total RNA was reverse-transcribed with the SuperScript ${ }^{\mathrm{TM}}$ III FirstStrand Synthesis System (Invitrogen, Karlruhe, Germany) for real-time PCR according to the manufacturer's instructions. Quantitative real-time PCR was performed with 2× Quanti Tect SYBR Green PCR Master Mix (Qiagen, Hilden, Germany) and the 7900HT Fast Real-Time PCR System (Applied Biosystems, Darmstadt, Germany). cDNA quantities were measured as critical threshold $\left(C_{T}\right)$ values, which were then normalized using simultaneously measured $\beta$-actin levels $\left(\Delta \mathrm{C}_{\mathrm{T}}\right)$. Final $\Delta \Delta \mathrm{C}_{\mathrm{T}}$ values were obtained by comparing bacteria-stimulated or TNF $\alpha$-treated cells with unstimulated cells using PCPECs from three different preparations. Primers used were previously described [26] (Table 2). The specificity of PCR products was checked by agarose gel electrophoresis (data not shown).

\section{Measurement of cell viability}

Cell vitality was measured using the Live/Dead ${ }^{\circledR}$ Viability/Cytotoxicity Kit for mammalian cells (Molecular Probes, Göttingen, Germany) according to the manufacturer's instructions. The results were photodocumented by fluorescence microscopy. In all experiments no cytotoxicity was observed (data not shown).

\section{Statistical analysis}

All data are expressed as means \pm standard deviation (SD) as indicated. TEER, dextran-flux, FACS analysis and real-time PCR data were analyzed by Student's $t$ test respectively, PMN transmigration data by an

Table 2 Primers used for quantitative real-time PCR

\begin{tabular}{lll}
\hline Gene & Primer & Sequence $\left(\mathbf{5}^{\prime} \boldsymbol{\rightarrow} \mathbf{3}^{\prime} \mathbf{)}\right.$ \\
\hline ICAM-1 & forward & CACAGGCCGCCACTAACAA \\
ICAM-1 & reverse & GGTTCCATTGATCCAGGTCTT \\
VCAM-1 & forward & GCACGAGCTTCCTGAGCACTT \\
VCAM-1 & reverse & CTGTGTGACGAGGAAACAATG \\
$\beta$-actin & forward & TCCAGAGGCGCTCTTCCA \\
$\beta$-actin & reverse & CGCACTTCATGATCGAGTTGA \\
\hline
\end{tabular}

ICAM, intracellular adhesion molecule; VCAM, vascular cell adhesion molecule. analysis of variance (ANOVA) with repeated measurements and the method of compound symmetry was performed. $P$-values for post-hoc test were adjusted by the method of Tukey-Kramer. The procedure of MIXED of SAS was used. A $P$ value of $<0.05$ was considered significant. All assays were repeated at least three times. Texas Red-dextran flux data were expressed as percent of tracer in the basolateral compartment.

\section{Results}

\section{IL-8 and PMN transmigration itself do not alter PCPEC} barrier function

For human brain microvessel endothelial cells (HBMECs), it has been described that PMN transmigration leads to a loss of blood-brain barrier function, which is determined by a drop in TEER and enhanced paracellular permeability [27]. To determine whether this also applies for the blood-CSF barrier we measured TEER and paracellular TR-dextran flux in bacterially stimulated and unstimulated PCPEC in our previously described inverted Transwell filter system [4] (Figure 1A). Contrary to the results observed with HBMEC no significant changes in barrier function could be observed following PMN transmigration through unstimulated PCPECs in presence or absence of IL- 8 for up to 4 hours. Figure 1B shows no significant decrease of TEER during the incubation time of 4 hours in all tested conditions. In parallel, no significant increase in paracellular permeability was induced by IL-8, PMN or IL-8/PMN coincubation in comparison to control cells (Figure 1C).

\section{S. suis induces alteration barrier function in PCPECs in the presence of PMNs}

We were next interested in analyzing the influence of PMNs on PCPECs that had been infected with bacteria. Since previous studies have demonstrated an increased permeability caused by $\mathrm{TNF} \alpha$ in cellular barriers, especially for brain endothelial cells [28] and PCPECs in a standard Transwell system [26], we used this cytokine for comparison with bacteria-infected PCPECs in the inverted Transwell filter cultures. In transmigration assays PCPECs were incubated with or without IL-8 in the lower filter compartment as a chemoattractant for PMN migration. TEER data are shown for simplicity only for IL-8-treated cells (Figure 2A), but results of experiments without IL-8 were not different indicating that IL-8 has no significant impact on barrier function (data not shown). Figure 2A shows a significant decrease of TEER to $24 \%$ of initial values after $24 \mathrm{~h}$ of TNF $\alpha$ stimulation. This goes in parallel with a significant 3-fold increase in paracellular permeability (Figure 2B). No significant changes in TEER were observed within the first 24 hours under control conditions or after infection with S. suis strain 10 or the nonencapsulated mutant $10 \Delta \mathrm{cps}$. In contrast, after a 4-hour 


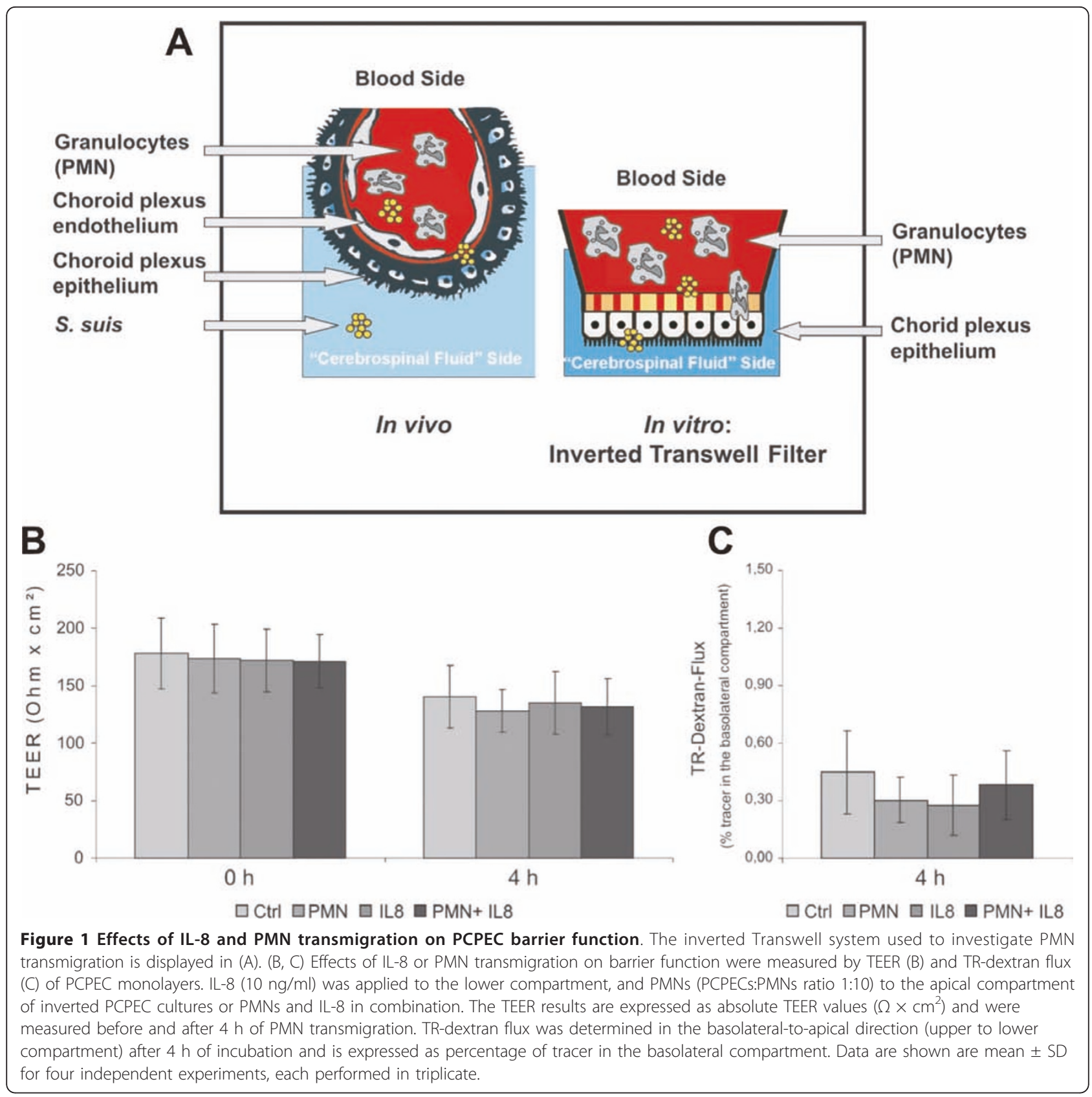

course of PMN transmigration we observed a significant drop of TEER after bacterial infection. However, the significant TEER drop caused by TNF $\alpha$ stimulation alone did not change significantly after PMN migration. Paracellular TR-dextran flux remained low, but was nevertheless significantly enhanced by $S$. suis strain 10 and strain $10 \Delta$ cps stimulation compared to controls, whereas bacteria- and TNF $\alpha$-induced paracellular fluxes did not differ significantly from each other. In line with the TEER analyses, no differences in TR-dextran fluxes could be observed for IL8 -treated and control cells.

\section{S. suis and TNF $\alpha$ induce PMN transmigration through PCPECS}

After bacteria have entered the brain, the influx of leukocytes from the blood into the CNS is a crucial step in the development of meningitis. In our recent study we investigated transmigration of the well-encapsulated $S$. suis wild-type strain 10 and its capsule-deficient isogenic mutant strain $10 \Delta \mathrm{cps}$, and identified the capsule as a critical factor for adhesion to and invasion into PCPECs [4]. Infection of PCPECs from the physiologically relevant basolateral side with $S$. suis strain 10 (MOI 10) or 


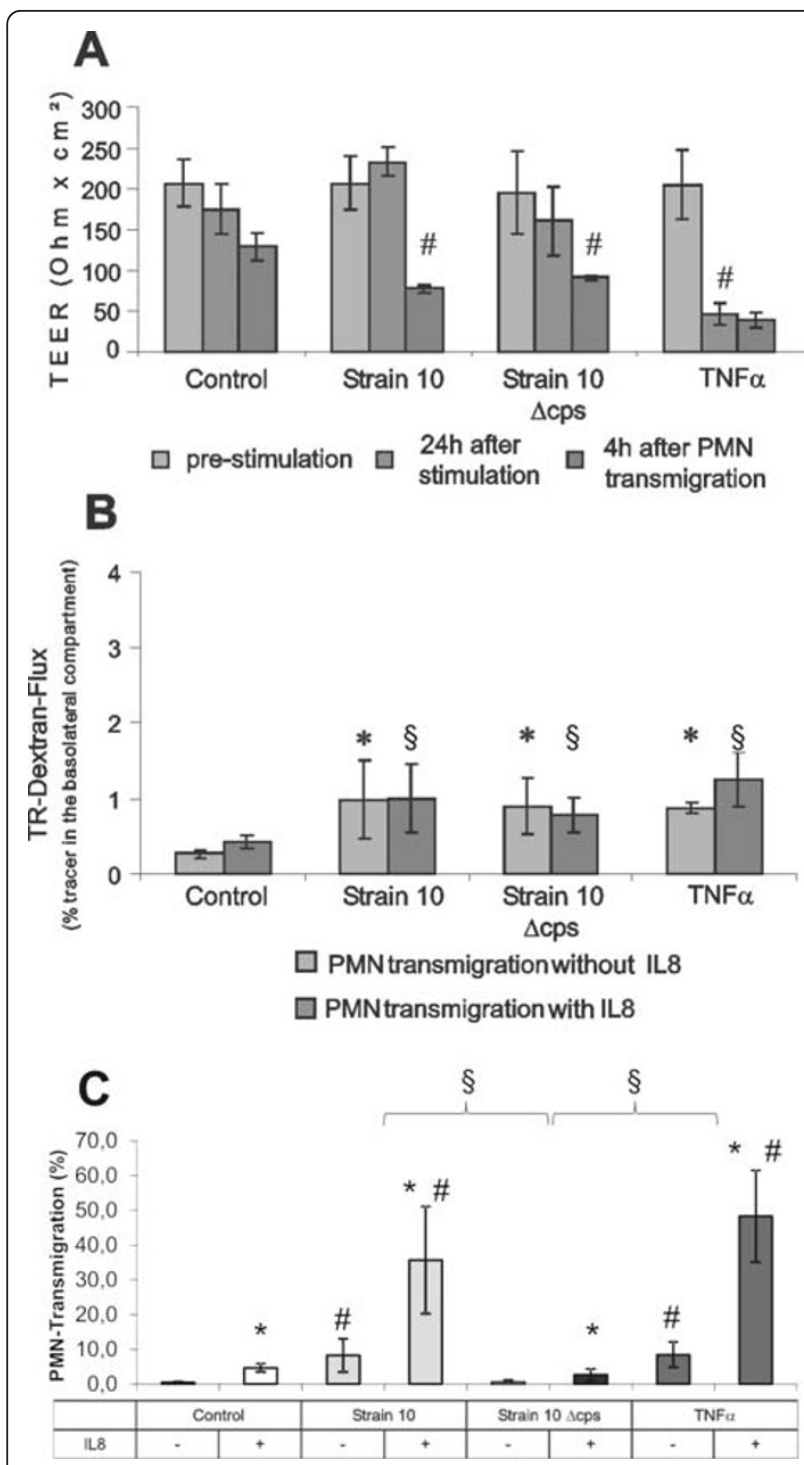

Figure 2 Effect of S. suis and TNF $\alpha$ on PMN transmigration through PCPEC and barrier function. (A, B, C) PCPECs were infected with $S$. suis strain 10 and the non-encapsulated mutant strain $10 \Delta \operatorname{cps}(\mathrm{MOI} 10)$ or stimulated with TNF $\alpha(10 \mathrm{ng} / \mathrm{ml})$ as described in Methods. PMNs were applied after $24 \mathrm{~h}$ of stimulation to the basolateral side of PCPEC. Effects on barrier function were measured by TEER (A) and TR-dextran flux (B) of PCPEC monolayers. The TEER results are expressed as absolute TEER values $\left(\Omega \times \mathrm{cm}^{2}\right)$. (A) For simplification only TEER values of IL-8-treated PCPECs are shown because they did not differ from TEER values of PCPEC cultures without IL-8. TEER was measured before stimulation, $24 \mathrm{~h}$ later that was directly before PMN transmigration and after $4 \mathrm{~h}$ of PMN transmigration. \#, P value of $<0.001$, compared to time point before.(B) The TR-dextran flux was measured in the basolateral-toapical direction (upper to lower compartment) with or without $\mathrm{S}$. suis infection, respectively, and TNF $\alpha$ stimulation and is expressed as percentage of tracer in the basolateral (upper) compartment. TRdextran flux was determined after $4 \mathrm{~h}$ of PMN transmigration. In indicated samples $1 \mathrm{~L}-8(10 \mathrm{ng} / \mathrm{ml})$ was used as chemoattractant. Data are shown are mean \pm SD for four independent experiments, each performed in triplicate. ${ }^{*}, \mathrm{P}$ value of $<0.05$ compared to corresponding control PCPECs without IL-8 stimulation. §, P value of
$<0.05$ compared to corresponding control PCPECs with IL-8 stimulation. (C) BCECF-loaded PMNs were applied after $24 \mathrm{~h}$ of stimulation to the basolateral side of inverted PCPEC in a PCPECs: PMNs ratio of $1: 10$. In indicated samples $\mathrm{LL}-8(10 \mathrm{ng} / \mathrm{ml})$ was used as chemoattractant. The number of PMNs was fluorometrically measured after $4 \mathrm{~h}$ of transmigration. PMN transmigration is expressed\% PMN transmigration from totally applied PMNs. Data are shown as mean \pm SD for four independent experiments, each performed in triplicate. ${ }^{*}, \mathrm{P}$ value of $<0.0001$ compared to PCPEC without IL-8; \#, P value of $<0.0001$, compared to corresponding control PCPEC +/- IL-8; §, P value of $<0.0001$ compared between different stimuli.

apical and basolateral stimulation with TNF $\alpha(10 \mathrm{ng} / \mathrm{ml})$ leads to significant PMN transmigration (Figure 2C). In contrast, infection with the capsule-deficient mutant strain $10 \Delta$ cps did not cause an increased PMN migration rate; in fact this was significant lower than in $S$. suis strain 10 or TNF $\alpha$-treated cells, and comparable to that of control cells. In control cells as well as in S. suis or TNF $\alpha$-treated cells the transmigration rate could be further significantly increased by the chemoattractant IL-8. In a second set of experiments we infected PMNs directly with $S$. suis strain 10 or strain $10 \Delta \mathrm{cps}$ (MOI 10 ) and subsequently performed PMN migration assays with IL-8-treated cells. We again observed a significantly lower transmigration rate after stimulation with the capsule-deficient strain, and for both $S$. suis strains a significant reduction of PMN transmigration rate compared to uninfected control PCPECs (data not shown). Moreover, TEER and paracellular TR-dextran flux of S. suisinfected cells were not significantly compromised compared to uninfected control PCPECs (data not shown).

\section{Tight junction and actin cytoskeleton morphology after PMN transmigration}

The next set of experiments was performed to test if changes in barrier properties induced by S. suis, TNFa and PMN correlate with morphological changes in TJ and actin cytoskeleton distribution. S. suis-infected and especially TNF $\alpha$-stimulated PCPECs co-incubated with (Figure 3,4) or without PMNs (data not shown) showed a fuzzy and blurred distribution pattern of ZO-1 (Figure $3 E, I, M)$ and occludin changes (Figure 4E, I, M), whereas control cells incubated with or without PMNs displayed a more clear and smooth protein expression at the cell borders (Figure 3A, 4A (and data not shown)). Stimulation of PCPECs especially with TNF $\alpha$ led to a decreased staining pattern of the TJ proteins ZO-1 and occludin, indicating stronger alteration and partial loss of the TJ proteins, which goes in line with our previously published results in the standard Transwell system $[3,26]$. The phalloidin-stained actin cytoskeleton of unstimulated control cells incubated with or without 


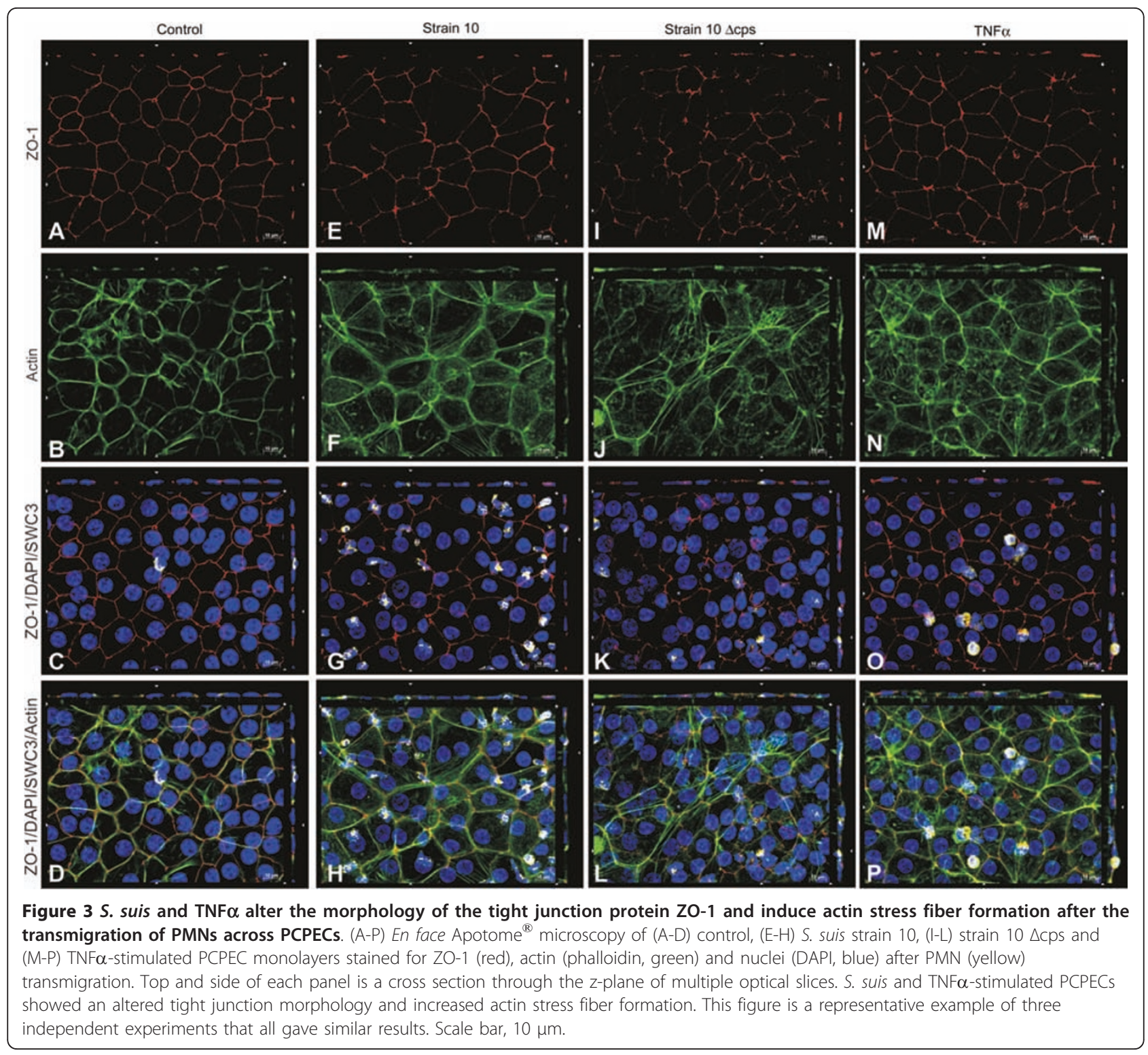

PMNs showed very clear structures and well-defined perijunctional apical actin rings (Figure 3B, 4B (and data not shown)). After co-stimulation of PCPECs with bacteria or TNFa in the presence or absence PMNs the appearance of the actin cytoskeleton changed from clear structures to a diffuse actin staining in the apical and basolateral cell compartment, with reduced colocalization with ZO-1 or occludin, and stress fiber formation (Figure 3F, J, N; Figure 4F, J, N (and data not shown)). Stress fibers appeared partly in cabled bundles in the basolateral cell compartment.

\section{Transcellular PMN traversal through PCPECs}

Next we performed detailed and sequential microscopic studies to elucidate the PMN transmigration process.
Three dimensional immunoflourescence analyses show PMNs in different phases of PMN migration through unstimulated cells (Figure 5), S. suis strain 10 (Figure 6), $S$. suis strain $10 \Delta$ cps (Figure 7) and TNF $\alpha$ - (Figure 8) stimulated cells. In Figure 5A-E and 6A-E the PMN is located in the centre of the cell that it has almost completely crossed. The PMN is also seen in a position relative to the PCPEC cell nucleus. An elongated PMN below a TJ strand is shown in uninfected cells (Figure 5F-J). Figure 6F-J show a PMN that still lies under the TJ strands at a tricellular corner within the PCPEC monolayer (Figure 6I, J), where ZO1 is structurally altered (Figure 6F) and the actin cytoskeleton shows a strong condensation (Figure 6G, H). The main part of the PMN is found within the PCPEC cell level (Figure 6I-J). Figure 6K-O, indicates PMN migration 


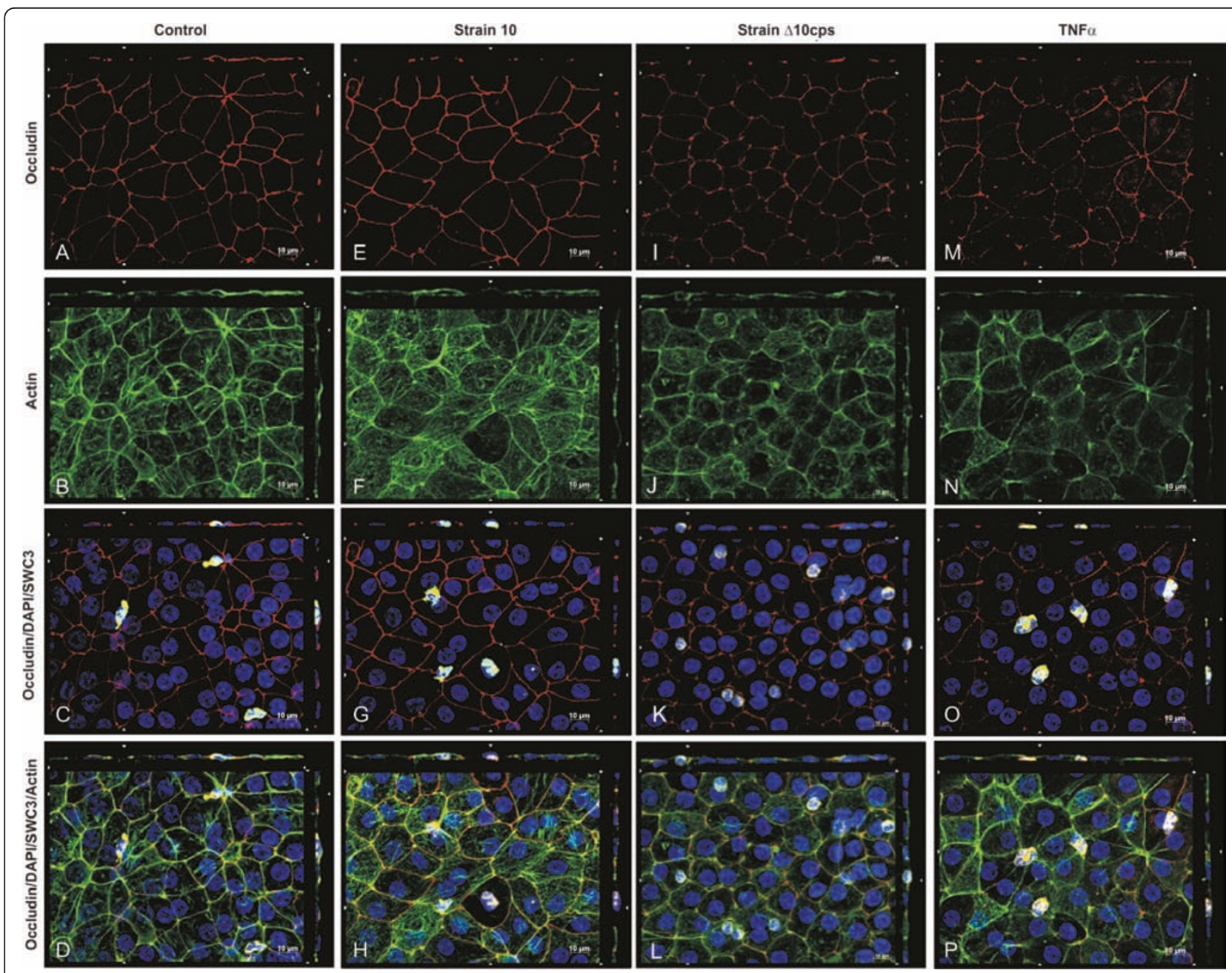

Figure $4 \mathrm{~S}$. suis and TNF $\alpha$ alter the morphology of the tight junction protein occludin and induce actin stress fiber formation after the transmigration of PMNs across PCPECs. (A-P) En face Apotome microscopy of control (A-D), S. suis (strain 10: E-H, strain $10 \triangle \mathrm{cps}$ : I-L) and TNF $\alpha$ - (M-P) stimulated PCPEC monolayers stained for occludin (red), actin (phalloidin, green) and nuclei (DAPI, blue) after PMN (yellow) transmigration. Top and side of each panel is a cross section through the z-plane of multiple optical slices. This figure is a representative example of three independent experiments that all gave similar results. Scale bar, $10 \mu \mathrm{m}$.

along altered tight junctions, but not through them. Immunofluorescence analyses of different phases of PMN migration through S. suis strain $10 \Delta$ cps and TNF $\alpha$-stimulated cells showed similar findings and an altered tight junction morphology close to a PMN (Figures 7, 8).

Electron microscopical investigations were performed in order to further describe the mode of transmigration of PMNs through the PCPEC monolayer. We compared orthogradely sectioned filters with filters sectioned nearly parallel through the apical surface to allow better interpretation of cellular details during transmigration. In Figure 9A, we see a PMN directly associated with two CP cells interconnected by a tight junction (arrow). The PMN is closely squeezed between the two epithelial cells, but it appears that the cell is not able to overcome the tight junction-based barrier beneath the microvilli.
In $9 \mathrm{~B}$, an intracellular location of the largest portion of a PMN within an epithelial cell is shown. Intracellular location in this context means that a PMN is in a vacuolar structure and not in the cytoplasm. The arrow points to the intact tight junction, which is clearly distant from the transmigrating cell. In $9 \mathrm{C}$ and 9D, another example is shown of the inability of a PMN to open the tight junction (arrow in 9D) but, in parallel, the PMN tries to enter the epithelial cell in order to reach the surface of the epithelial cell which is strongly enlarged by numerous microvilli. In addition, the lower magnification in $9 \mathrm{C}$ suggests an indentation of the apical surface of the epithelial cell layer forming funnel-like structures (asterisks in 9C). These indentations were as well lined by many microvilli proving again these membranes as apical ones. We termed these indentations 


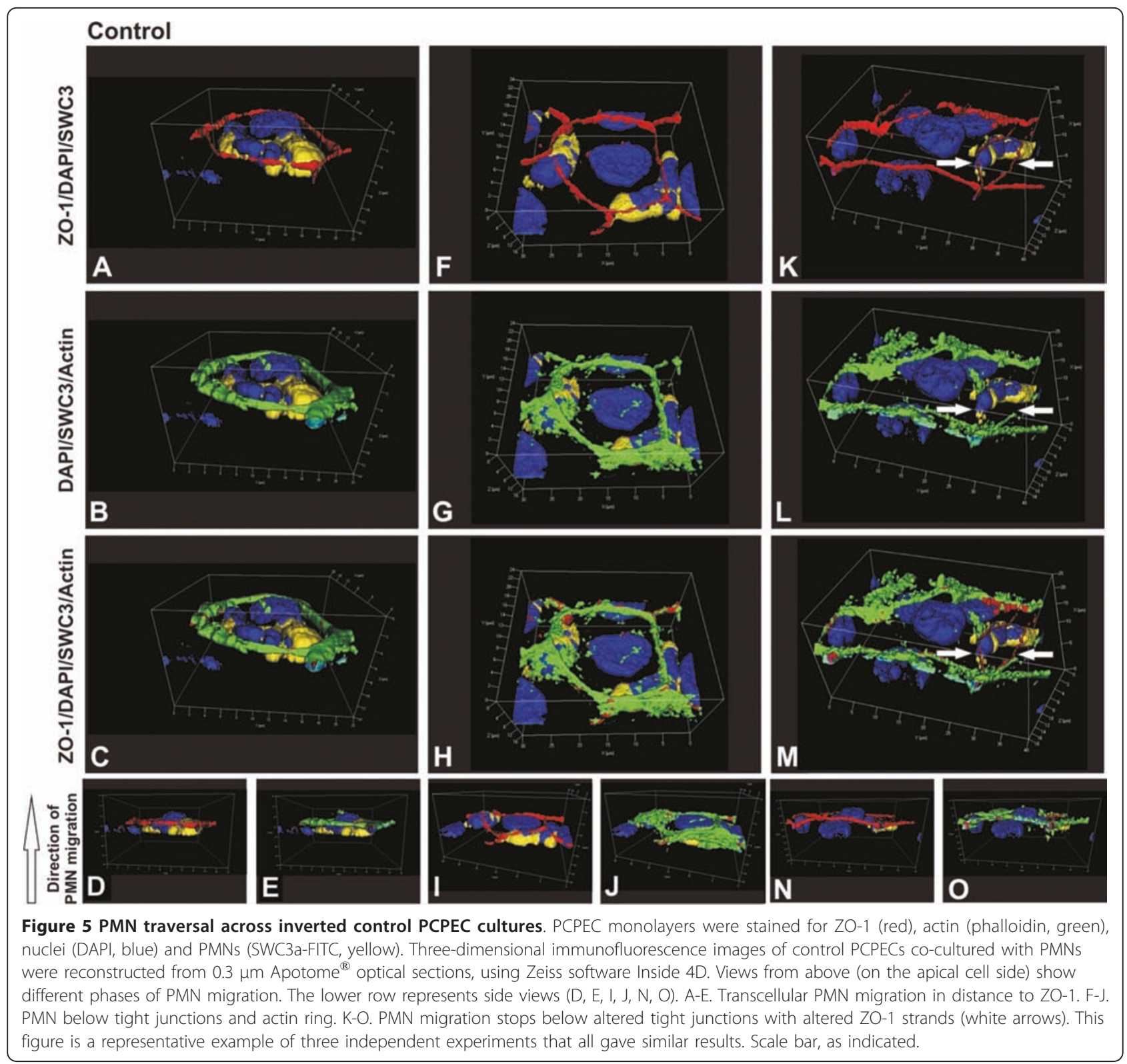

funnel-like structures and assumed that they are the preferred locations where the transcellular transmigration could occur. The area shown in 9D at a higher magnification is labelled in $9 \mathrm{C}$ by a thick arrow. A similar funnel cross-sectioned in a flat section parallel to the filter is shown in 9E by asterisks. The area that is shown in higher magnification in $9 \mathrm{~F}$ is labelled by a thick arrow in 9E. The section runs parallel or slightly oblique to the apical surface of the monolayer. The PMN is completely surrounded by vesicular membranes which, in the REM investigation (Figure 10E), can be identified as formed by the PMN itself. Again, the tight junction (thin arrow) remains closed and unaffected. Another striking finding was the presence of bacteria in large vacuoles within PMN during transmigration through PCPEC (Figure 9G-J). We made this observation, which suggests a traversal mechanism known as "Trojan horse", with $S$. suis strain $10 \Delta$ cps (Figure 9I,J) as well as with the wild-type strain (Figure 9G,H).

In scanning electron microscopic images PMNs were regularly found directly on the apical surface of the monolayer and at a distance from the intercellular clefts (Figure 10). Due to the possibility that, after completion of transmigration, the PMN can migrate over the surface of the epithelial cells, the site of former transmigration in principle cannot be determined unequivocally. However, the cell in 10A and the lower cell in $10 \mathrm{~B}$ could have overcome the barrier in the middle of an 


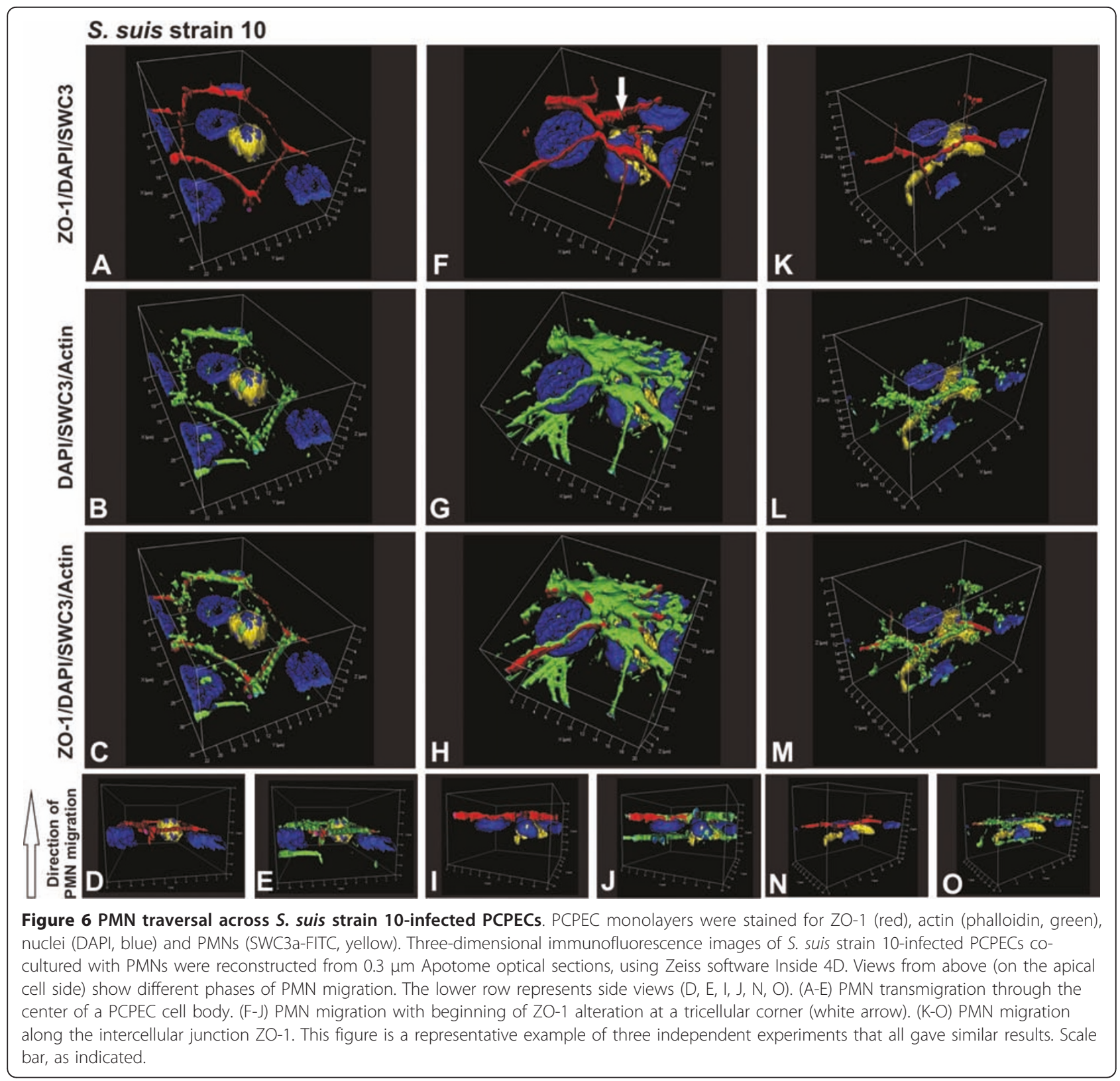

epithelial cell, apart from the cell border, whereas the smaller cell in 10B, and also the cell in 10C, could have just transmigrated between two epithelial cells. In 10D, a PMN lies in an indentation in the middle of an epithelial cell, corresponding to the funnel-like structure described in Figure 9 and below. In 10E, the vesicular structures (asterisks) of a transmigrating PMN are shown which correspond to the surface folding of the PMN in ultrathin sections (asterisks in Figure 9F). Finally, 10F shows a preparation artefact allowing a look into the space below the surface of the epithelial monolayer, where a PMN is waiting to transmigrate (the arrow points to the expected direction of the cell). Here it seems evident that the PMN will transmigrate transcellularly, because no cellular border can be observed. In Figure $11 \mathrm{~A}-\mathrm{C}$ we investigated the funnel-like indentations of the cell layer of a TNF $\alpha$-stimulated PCPEC and performed serial sections parallel to the Transwell filter at intervals of $2-3 \mu \mathrm{m}$. In the middle, we have the crosssectioned funnel lined by a seam of microvilli and rare cilia of one cell (a basal body of a cilium is labelled by an arrow in 9I, proving that this surface is the apical surface of the epithelial cell). Obviously, PMNs take the route via the funnel to overcome the epithelial barrier. In this, identical cell profiles in the different pictures are numbered correspondingly. It is a striking observation 


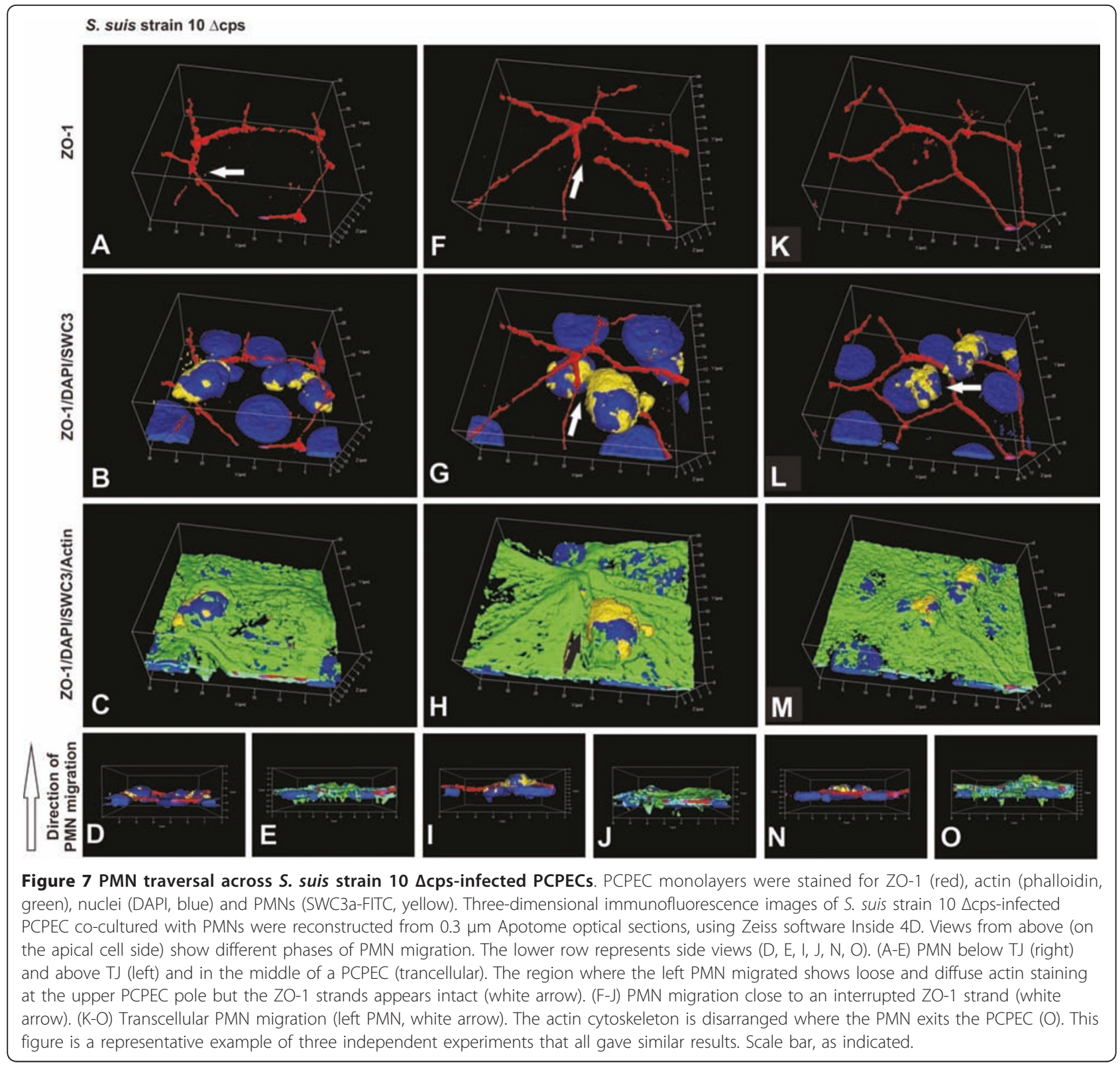

that such funnels are regularly found adjacent to PMNs. We observed these funnel-like structures in S. suis or TNF $\alpha$-stimulated as well as unstimulated PCPECs, but only in the presence of PMNs (data not shown).

\section{PMN transmigration through PCPECs is CD11b/CD18 dependent}

The cellular and molecular mechanisms of PMN transmigration through epithelial cell layers are still largely under investigation. To identify the integrins that play a role in PMN transmigration from the blood side through CP epithelium, we performed inhibition studies with antibodies cross-reacting to porcine cell surface molecules, which have largely been described [23,24].
Binding of these antibodies to their respective epitopes was confirmed by FACS analyses as described in Methods. A significant effect could be detected after preincubation of PMNs with anti-CD11b and anti-CD18, but not with anti-CD11a (Figure 12A). Moreover we tested the inhibitory properties of antibodies specific to the $\alpha_{4}$-integrin CD49d (VLA-4), the $\alpha_{5}$-integrin CD49e (VLA-5) and the integrin-associated glycoprotein CD47 to reduce PMN transmigration. Neither anti-CD49d nor -CD49e pre-incubated with PMNs, nor anti-CD47 on epithelial cells could diminish their transmigration rate (data not shown). Combinations of anti-CD47 and antiCD11a, -CD11b and -CD18 showed also no additive inhibitory effects (data not shown). The transmigration 


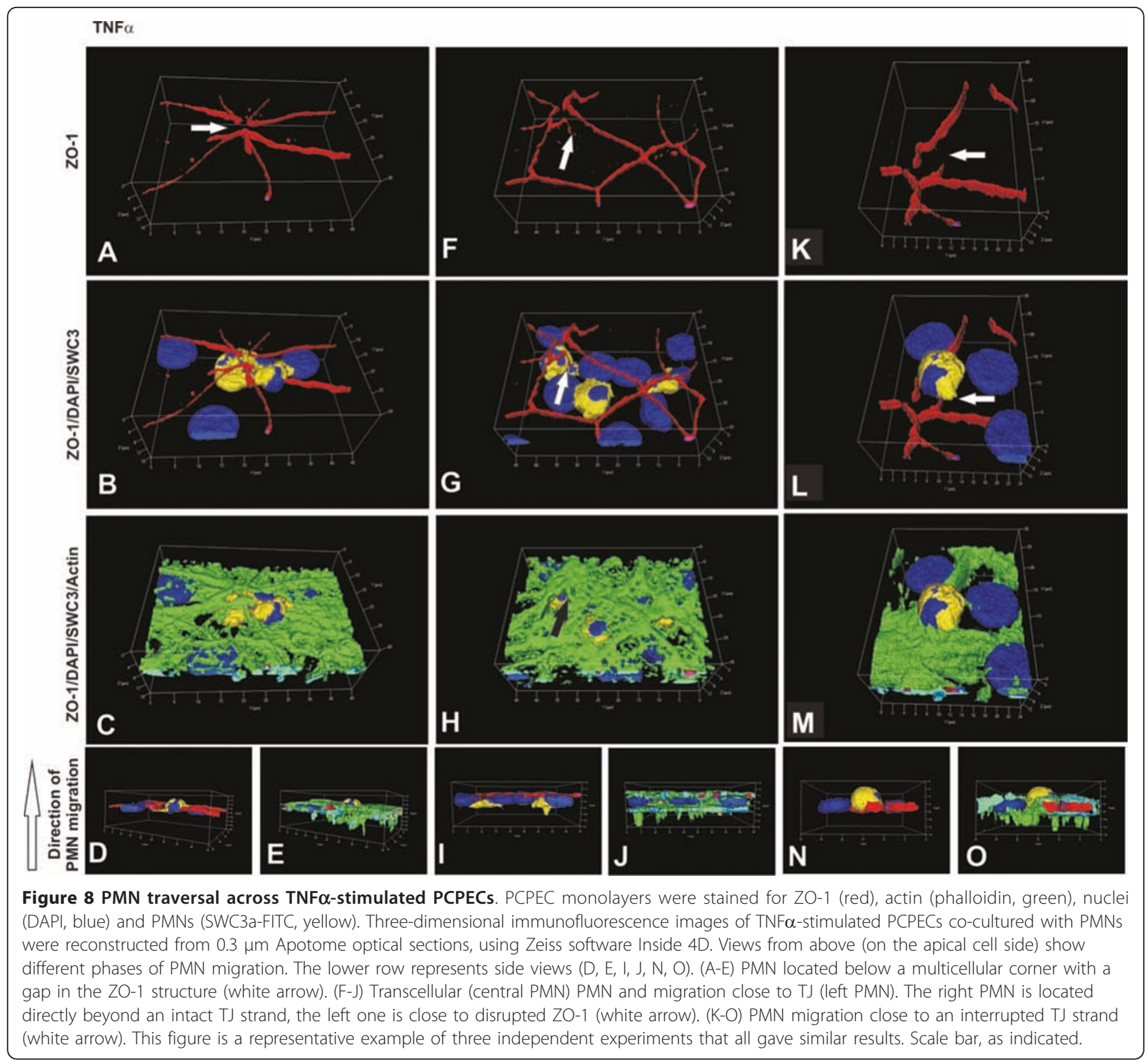

of PMNs primed with isotype controls was comparable to that of untreated PMNs for all conditions. To clarify if antibodies themselves compromised barrier function we also measured TEER and paracellular TR-dextran flux and found no significant influence (data not shown).

To validate the observed inhibitory effects of antibodies against CD11a, CD11b and CD18 in PMN transmigration assay we analyzed the expression patterns of these integrins on PMNs under different stimuli via flow cytometry. The presence of IL-8, which was used as chemoattractant in the assay, potentially stimulated the expression of PMN integrins [29]. Therefore, we investigated the effect of IL-8 and transmigration in principle on integrin expression in unstimulated control cells,
TNFa- and S. suis strain 10-stimulated cells. For transmigration assays $10 \mathrm{ng} / \mathrm{ml} \mathrm{IL-8} \mathrm{were} \mathrm{added} \mathrm{to} \mathrm{the} \mathrm{lower}$ compartment, which would lead to a concentration of $6.7 \mathrm{ng} / \mathrm{ml}$ in the whole well assuming an even distribution of IL- 8 in the upper and lower well by diffusion. Since it was impossible to determine the exact extent of the IL- 8 gradient in our experimental set-up, two different IL- 8 concentrations $(6.7$ and $10 \mathrm{ng} / \mathrm{ml})$ were applied, corresponding to the lowest $(6.7 \mathrm{ng} / \mathrm{ml})$ and the highest $(10 \mathrm{ng} / \mathrm{ml})$ possible concentrations. FACS analyses of PMNs after $S$. suis strain $10 \Delta$ cps stimulation was not possible due to the high background fluorescence of engulfed bacteria. During our flow cytometric analyses no significant differences between the two IL-8 concentrations were observed. The flow cytometric analyses of 

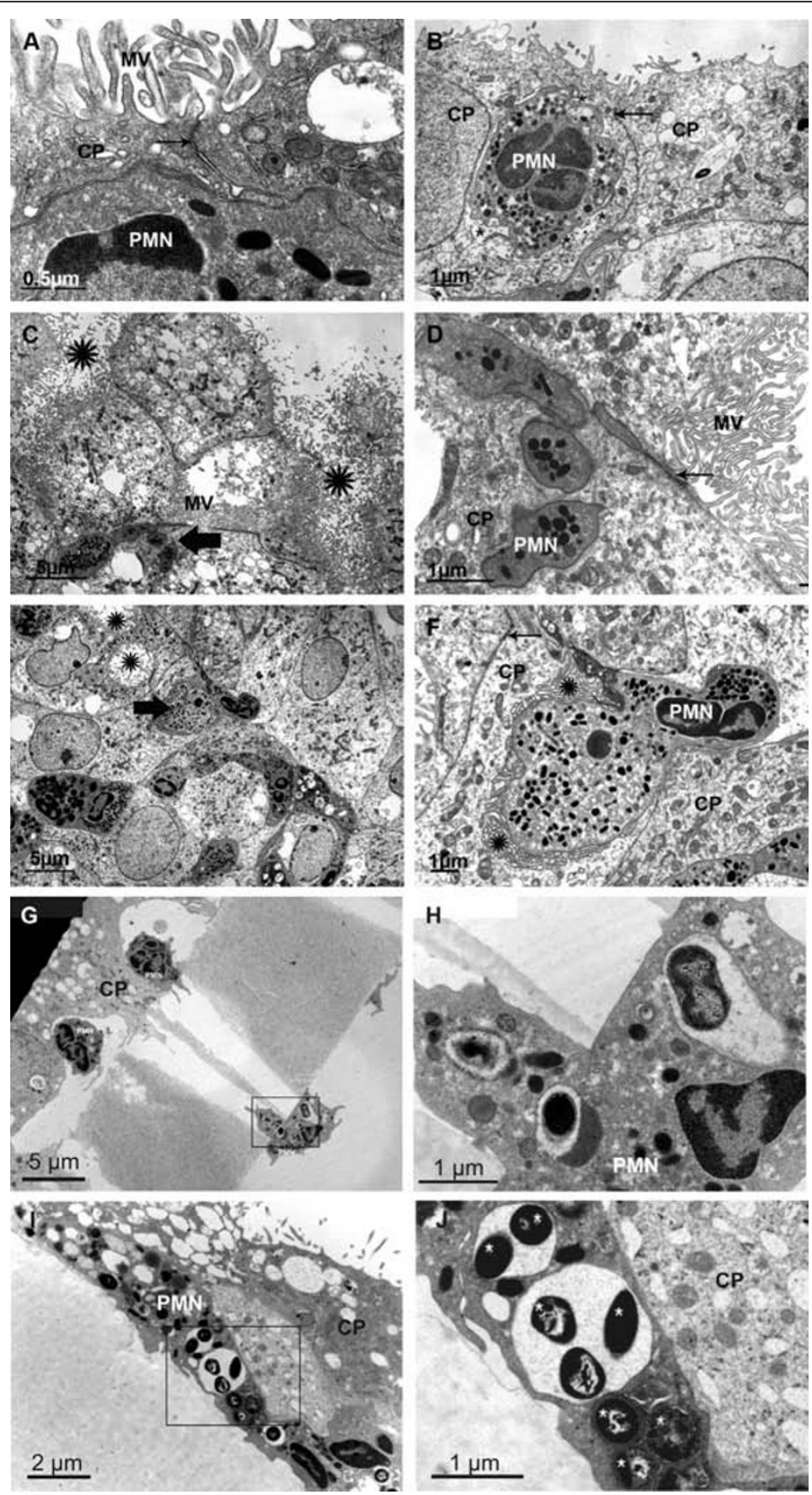

Figure 9 Electron microscopic view of a PMN travelling through the CP monolayer. (A, G, H) PCPECs were stimulated with S. suis strain 10, $(\mathrm{B}, \mathrm{I}, \mathrm{J}) \mathrm{S}$. suis strain $10 \triangle \mathrm{cps}$ or (C-F) TNF $\alpha$. (A) A PMN is closely associated to two epithelial cells (CP), near the tight junction (thin arrow). MV = microvilli. (B) In this case, the PMN has nearly touched the apical membrane for release of the cell into the upper compartment. The tight junction is labelled by an arrow. The space between the PMN and the epithelial cell (CP) is labelled by small asterisks. (C) Inability of PMN to open the tight junction, but in parallel, the PMN tries to enter the epithelial cell in order to reach the surface of the epithelial cell which is strongly enlarged by numerous microvilli (MV). In addition, the lower magnification in C suggests an indentation of the apical surface of the epithelial cell layer forming funnel-like structures (asterisks in C). (D) The area shown in D at higher magnification is labelled in C by a thick arrow. (E) A similar funnel is cross-sectioned in a flat section parallel to the filter (asterisks). (F) Higher magnified area labelled by a thick arrow in (E). The section runs parallel or slightly oblique to the apical surface of the monolayer. The PMN is completely surrounded by vesicular membranes which, in the REM investigation (Figure 5E), can be identified as formed by the PMN itself. Again, the tight junction (thin arrow) remains closed and unaffected. (G) PMN harbouring encapsulated S. suis strain 10 in vacuoles. (H) Enlargement of the marked section of G; bacteria are marked with a asterisks. (I) PMN harbouring non-encapsulated S. suis strain $10 \Delta \mathrm{cps}$ in vacuoles (white marks). (J) Enlargement of the marked section of I; bacteria are marked with an asterisk. Scale bar, as indicated. 


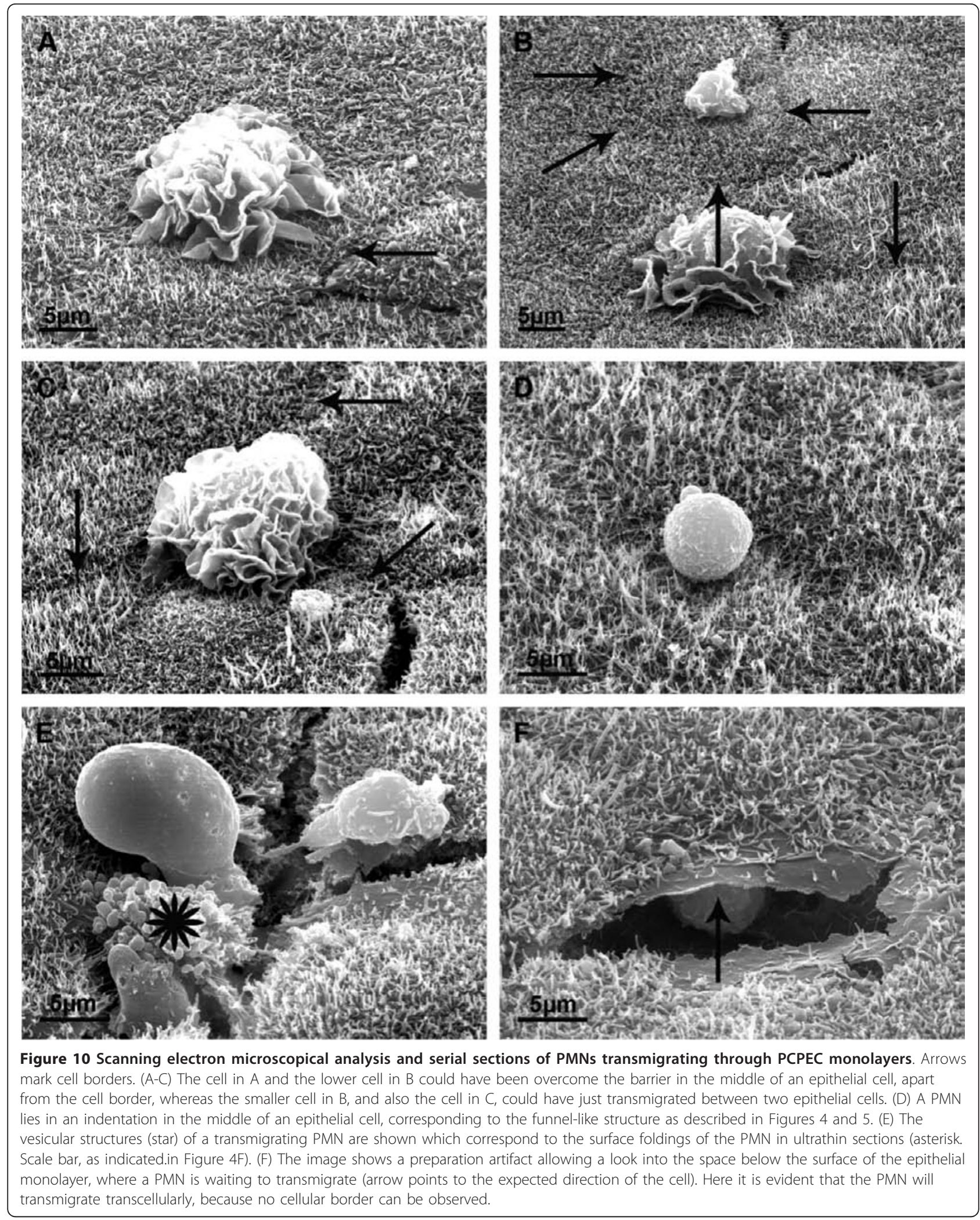




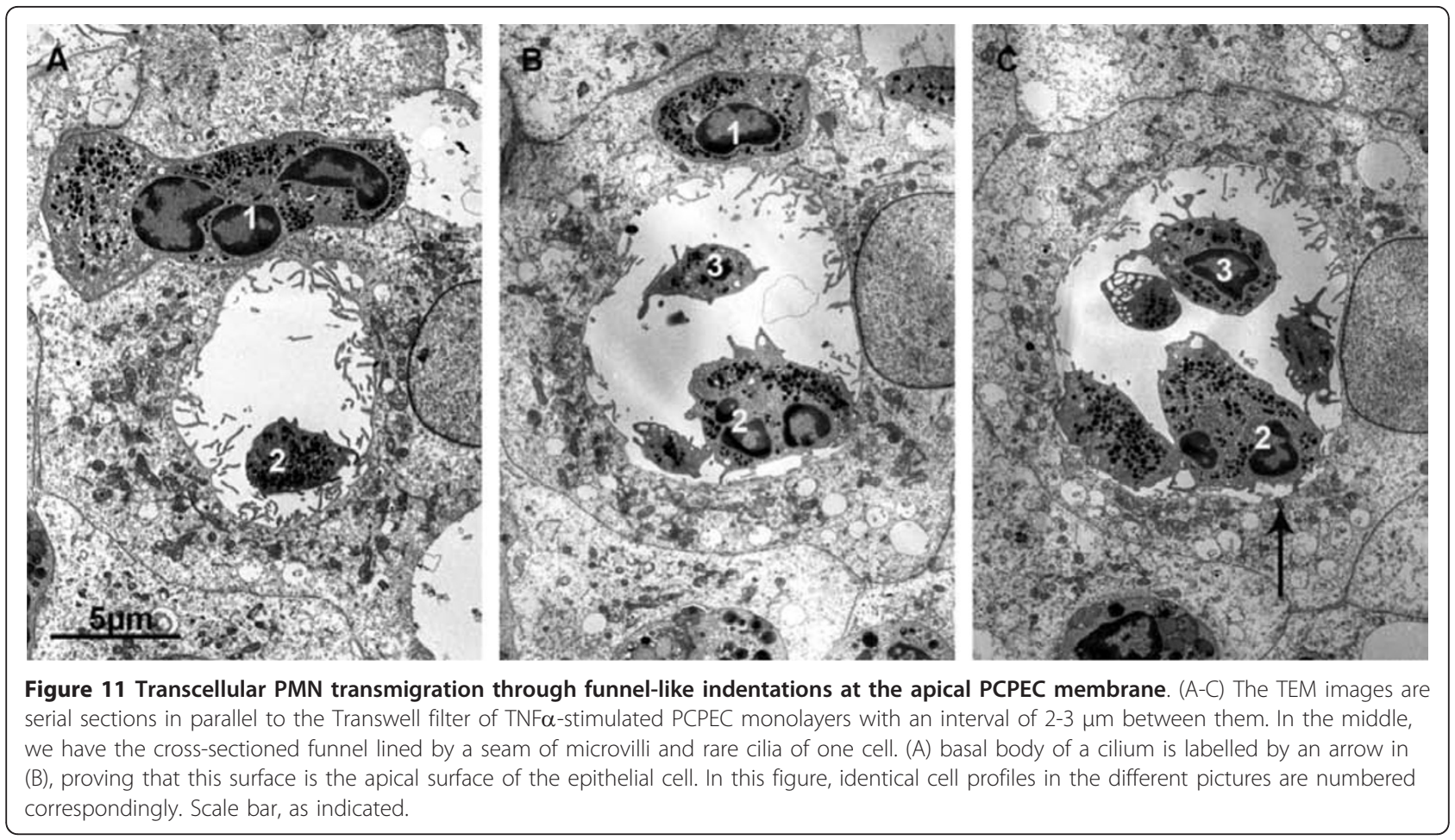

CD11a (Figure 12B) exhibited no differences in expression pattern before or after PMN transmigration for all tested stimuli. A significant increase of CD18 expression could be observed post-transmigration in control and $S$. suis treated cells, after IL- 8 stimulation and post transmigration in TNF $\alpha$-treated cells (Figure 12D). Corresponding to inhibition studies with anti-CD11b, we observed a significant upregulation of CD11b expression (Figure 12C). For all tested stimuli the expression pattern of CD47, CD49d and CD49e under IL-8 treatment or after transmigration were not altered in comparison to control cells (data not shown). This is consistent with inhibition studies, that showed no blocking effect of anti-CD47, -CD49d, and -CD49e antibodies on PMN transmigration.

\section{Effects of S. suis and TNF $\alpha$ stimulation on ICAM-1 and VCAM-1 mRNA expression}

As previously described, the mRNA expression for ICAM-1 and VCAM-1 is augmented in the PCPEC standard Transwell system under TNF $\alpha$ stimulation [26]. We now analysed mRNA expression of these cell adhesion molecules (CAMs) under bacterial infections with the encapsulated $S$. suis strain 10 and its non-encapsulated isogenic mutant strain $10 \Delta \mathrm{cps}$ in comparison to unstimulated control and TNF $\alpha$-stimulated cells in the inverted Transwell system (Figure 13). Using a quantitative real time-PCR technique we could observe that the mRNA expression levels for ICAM-1 and VCAM-1 remained low after $2 \mathrm{~h}$ of bacterial stimulation but already increased significantly under TNF $\alpha$ stimulation. The upregulation of VCAM-1 $\left(-\Delta \Delta \mathrm{C}_{\mathrm{T}} 7.5 \pm 1.1\right)$ was more intensive than that of ICAM-1 $\left(-\Delta \Delta C_{\mathrm{T}} 3.02 \pm\right.$ 0.08). After $4 \mathrm{~h}$ of stimulation, an intense upregulation of ICAM-1 as well as VCAM-1 could be detected after stimulation with S. suis, too. Upregulation of VCAM-1 was again significantly stronger than that of ICAM-1 for all stimuli. For both CAMs the mRNA expression induced by the non-encapulated mutant was higher than by the wild-type $S$. suis strain after 4 hours stimulation time but this was significant only for ICAM (ICAM-1: Strain 10 $-\Delta \Delta C_{\mathrm{T}} 1.5 \pm 0.1$, strain $10 \Delta \mathrm{cps}-\Delta \Delta \mathrm{C}_{\mathrm{T}} 2.6 \pm 0.2$; VCAM-1: Strain $10-\Delta \Delta C_{\mathrm{T}} 4.5 \pm 1.7$, strain $10 \Delta \mathrm{cps}$ $\left.-\Delta \Delta C_{\mathrm{T}} 6.4 \pm 1.2\right)$. TNFa caused the strongest effect on CAM expressions in PCPECs and was significantly higher compared to bacteria-stimulated cells (ICAM-1: $-\Delta \Delta \mathrm{C}_{\mathrm{T}}$ $5.5 \pm 0.5$, VCAM-1: $\left.-\Delta \Delta C_{\mathrm{T}} 10.8 \pm 1.1\right)$.

\section{Discussion}

One crucial step in the pathogenesis of bacterial meningitis after bacterial invasion into the CNS is the excessive infiltration of leukocytes into the cerebrospinal fluid leading to massive inflammation. To study PMN transmigration at the blood-CSF barrier, we used a recently established inverted Transwell filter model of PCPECs that enables investigation of leukocyte transmigration in the physiologically relevant basolateral-to-apical direction. [4]. This model displayed robust barrier properties, 


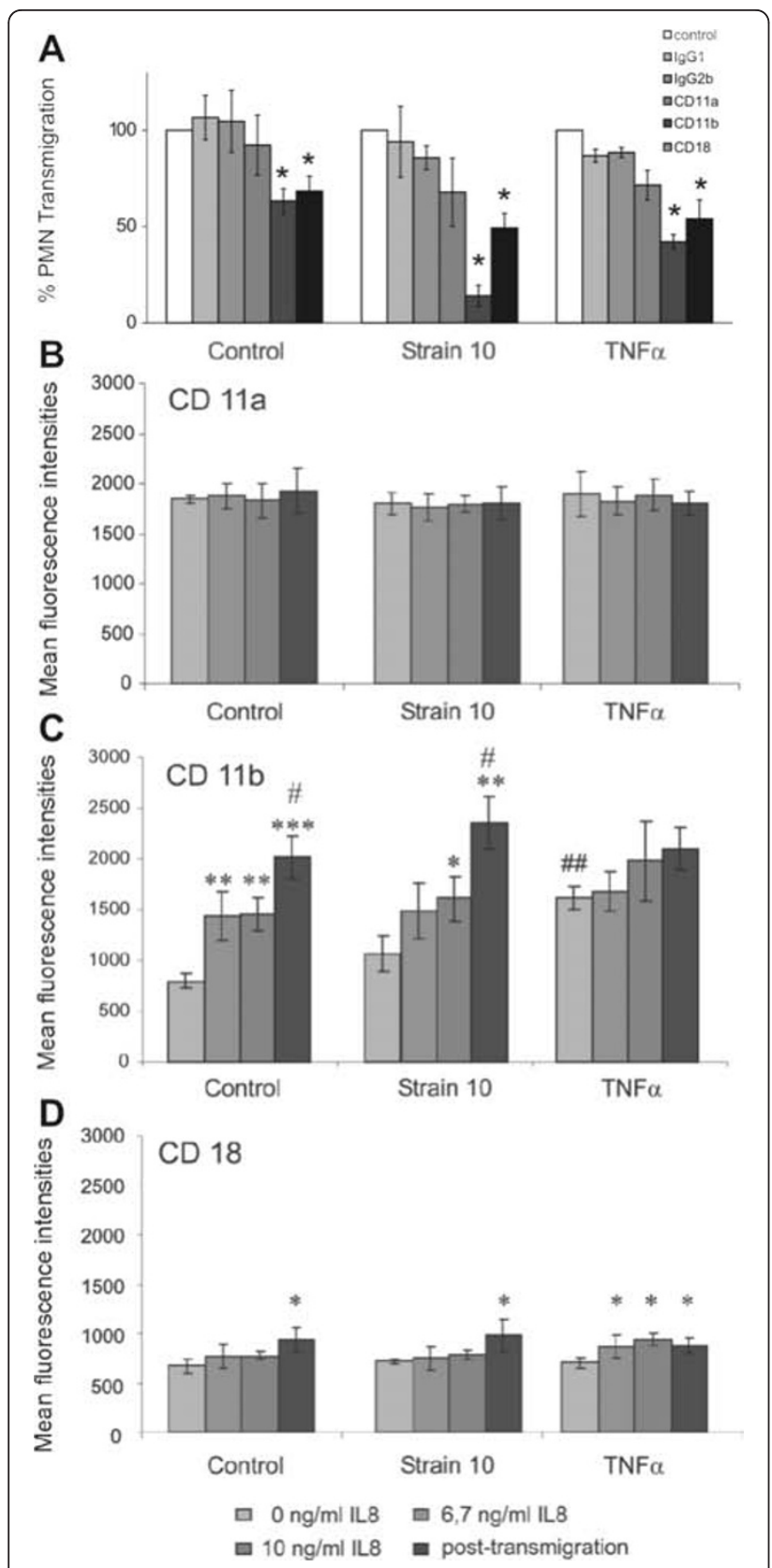

Figure 12 Inhibitory effects of integrin-specific antibodies on PMN transmigration and flow-cytometric analysis of integrin expression on PMNs dependent on IL-8 and PMN transmigration after $S$. suis infection or TNF $\alpha$ stimulation. (A) In blocking experiments PMNs were pre-incubated with antibodies specific to the PMN integrins CD11a, CD11b or CD18. PMN transmigration towards an IL-8 gradient $(10 \mathrm{ng} / \mathrm{ml})$ through nonstimulated and pre-stimulated PCPEC (S. suis strain 10 (MOI 10) or TNF $\alpha(10 \mathrm{ng} / \mathrm{ml}))$ was analyzed hereafter as described in the Method section. Data are presented as percent of migrated PMNs not pre-incubated with antibodies. Data are shown as mean \pm SD for four independent experiments each performed in triplicate. ${ }^{*}$, P value of $<0.05$ compared to unstimulated, respectively, stimulated PCPEC not pre-incubated with specific antibody. (B-D) Graph show the influence of different IL-8 concentrations combined with different stimuli on CD11a, CD11b or CD18 expression pre and post- transmigration. Results are presented as mean fluorescence intensities $\pm S D$ for 4 independent experiments. ${ }^{* *}, P$ value of $<$ 0.0001 ; ${ }^{* *}$, P value of $<0.01 ;{ }^{*}, \mathrm{P}$ value of $<0.05$ compared to PCPECs not stimulated with IL-8, \#, P value of $<0.01$ compared to cells treated with $10 \mathrm{ng} / \mathrm{ml} \mathrm{IL}-8$, \#\#, P value of $<0.01$ compared S. suis-treated and control cells.

which were not compromised by PMNs alone or the chemoatractant IL-8. The chemokine IL-8 (CXCL8) is known to interact with its cognate receptors CXCR1 and CXCR2. CXCR2 is the main receptor involved in neutrophil chemotaxis, leading to cell migration into the brain during injury, infection or disease [30]. Interestingly, although bacterial infection alone did not influence barrier function, TEER and paracellular TRdextran flux were significantly affected during the process of PMN traversal under bacterial stimulation, an effect that was already observed after treatment with TNF $\alpha$ alone. Nevertheless, the increased TR-dextran flux alone might not lead to paracellular transmigration of PMNs, since the observed compromise of tight junction function is still much lower than that of our own previously published results in the standard Transwell system after $S$. suis infection $[3,11]$. Conflicting data exist as to whether PMN transmigration itself can lead to significant barrier disruption, and this seems to depend on the cells and the stimulus used [27,31-33].

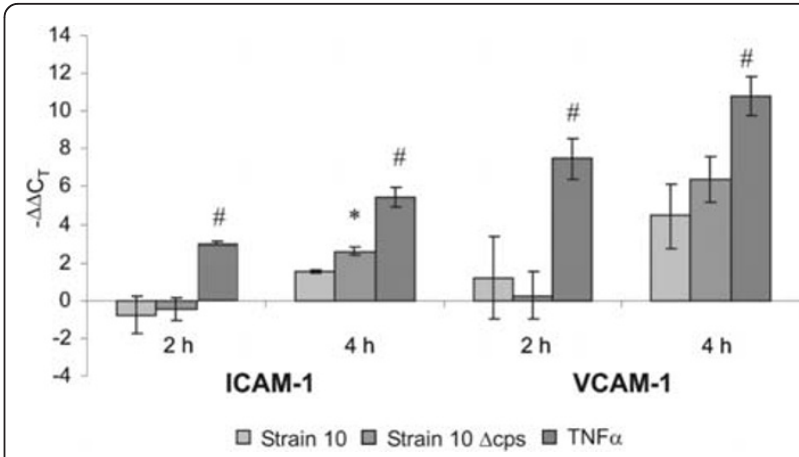

Figure 13 Effect of $S$. suis and TNF $\alpha$ on mRNA expression of ICAM-1 and VCAM-1. Quantitative real time-PCR analysing the effect of S. suis strain 10 (MOI 10), S. suis strain $10 \Delta \operatorname{cps}(\mathrm{MOI} 10)$ and TNF $\alpha(10 \mathrm{ng} / \mathrm{ml})$ on intercellular adhesion molecule-1 (ICAM-1) and vascular cell adhesion molecule-1 (VCAM-1) mRNA expression by porcine choroid plexus epithelial cells (PCPECs). Cells had been cultured on Transwell filters in the inverted system. Bacteria were added to the basolateral side (upper compartment) of the inverted cell cultures. TNF $\alpha$ stimulation was performed from basolateral and apical side. $-\Delta \Delta C_{T}$ values are based on $\beta$-actin standardization as well as on comparison to unstimulated control cells. Positive $-\Delta \Delta C_{T}$ values indicate an mRNA upregulation. Results are presented as means \pm SD for at least 3 independent experiments. \#, $P$ value of $<$ 0.01 compared to bacteria-stimulated PCPECs, ${ }^{*} P$ value of $<0.05$ compared to S. suis strain 10 
The alteration of barrier function after PMN transmigration following infection with $S$. suis or by TNF $\alpha$ stimulation was associated with an altered actin cytoskeleton and TJ morphology. Independently of the presence of PMNs, both stimulations led to stress fiber formation and an actin rearrangement within the cells, and a fuzzy and blurred distribution pattern of ZO-1 and occludin. In contrast, TEER of PCPECs was not significantly affected by $S$. suis infection alone. Corresponding changes in PCPECs in immunofluorescence analyses of tight junction and cytoskeletal actin morphology were not as strong as described earlier by our group and Zeni and co-workers in the standard Transwell system, which might explain the lower effect on barrier function $[3,26]$. Interestingly, in the present study the TJ structure was specifically altered in areas where PMNs crossed the PCPEC monolayer between cells (as described in Figures $5,6,7,8)$. Therefore, local changes in PCPEC morphology may correspond to minor or no TEER decrease. Changes in actin rearrangement may also not necessarily go along with a dramatic decrease of TEER. To maintain barrier function during paracellular transepithelial migration, close cell-cell contact and highly regulated mechanisms are necessary for opening and closing of the TJ $[34,35]$.

Infection with the well-encapsulated S. suis wild-type strain 10 and stimulation with the proinflammatory cytokine TNF $\alpha$ led to an augmented PMN traversal in both the presence and absence of IL-8. This goes in line with results that TNF $\alpha$ stimulation of HBMEC or renal proximal tubular cells leads to increased PMN transmigration $[27,36]$. Interestingly, the stimulation of PCPECs with $S$. suis strain $10 \Delta$ cps caused no increase of PMN transmigration. S. suis strain $10 \Delta \mathrm{cps}$ may have induced cell signalling in PCPECs or PMNs that prevented PMN transmigration. Previous results of Chabot-Roy et al. have shown an increased PMN phagocytosis rate of $S$. suis strain $10 \Delta$ cps compared to the wild-type, which may also influence the transmigration capacity of PMN [37]. Further experiments are necessary to clarify these questions.

For transendothelial migration a paracellular route between adjacent cells has been postulated for a long time, but in the meanwhile the transcellular route directly through the endothelial cell body has been well documented $[14,15]$. In contrast, there is to date no evidence that PMNs take the transcellular route through epithelial cells $[12,13]$. The concert of experimental techniques applied in this study consistently suggests a general preference of neutrophils for transcellular transmigration pathways across PCPECs. By means of immunofluorescence and transmission and scanning electron microscopy analyzes we were indeed able to provide evidence for migratory events through one single cell.
However, in determining the transmigration route of PMNs through PCPECs, we were confronted with the problem that neither our immunofluorescence nor electron microscopic images were absolutely unequivocal. If, for example, a leukocyte appears to lie inside a plexus epithelial cell, this could be interpreted simply as transcellular migration. However, the cell migrating along the intercellular cleft could be sectioned in a way that would allow us to interpret the position of the cell falsely as an intracellular one. Intracellular location in this context is defined as a PMN that is in a vacuolar structure and not in the cytoplasm. By definition, guest cell and host cell form a double membrane. However, the difficulty consists in determining whether the guest cell is only surrounded by the host cell in the section plane, while outside the section plane the cell could have contact with the extracellular space resembling an incomplete phagocytosis. We therefore compared orthogradely sectioned filters with filters sectioned nearly parallel through the apical surface to allow better interpretation of cellular details during transmigration. In every case the maintenance of the tight junctions was definitely observed by electron microscopy. Whether or not tight junctions in this system can be opened cannot be answered for principal reasons: we have currently no means to identify an opened junction. However, both $S$. suis or TNFa stimulation led to a fuzzy and blurred distribution pattern of ZO-1 as well as stress fiber formation and actin rearrangement within the cells as described earlier by our group and Zeni and co-workers in the standard Transwell system that may still promote paracellular PMN transmigration $[3,26]$. In scanning electron microscopic images PMNs were regularly found directly on the apical surface of the monolayer and at a distance from the intercellular clefts. Our data are in line with very recent findings by von Wedel-Parlow et al. [38], who demonstrated, in an in vitro model of the blood-brain barrier under inflammatory conditions, that PMNs preferentially migrate across primary cultured porcine brain capillary endothelial cells via the transcellular route.

Another striking observation in our experiments is that funnel-like structures were regularly found adjacent to PMNs protruding from the apical PCPEC membrane. We observed these funnel-like structures in stimulated as well as unstimulated PCPECs only in the presence of PMNs. The present funnel-like structures are apparently used by transmigratory PMNs, independent of their stimulatory status. However, we could not confirm the possibility that funnel-like structures are a conditio sine qua non for the transmigration of PMNs. Although we cannot unequovically exclude a completely paracellular process, our data imply that tight junctions induce a stop of paracellular migration and lead to a deviation of the PMN 
travelling route to involve a transcellular step via the indented apical compartment of the epithelial cell. This mechanism is to some extent different from the suggested paracellular transmigration of PMNs across the $\mathrm{CP}$ after brain injury [39]. In a mouse model it has been described that neutrophils of wild-type mice migrate predominantly paracellularly whereas CD11b/CD18-deficient mice use predominantly the transcellular pathway [40]. The reason for this difference is related to PMNs crawling to cell junctions that are absent in CD11b/ CD18-deficient PMNs. The increase in permeability was nearly identical for both forms of migration, because the endothelium forms a dome over the migrating neutrophil, which sealed the emerged gap and thereby limited alterations in vascular permeability independent of the migration route [18]. It should be noted that the two ways of transmigration - paracellular and transcellular are not mutually exclusive.

The exact routes and molecular mechanisms of PMN transmigration through epithelium are still not fully understood. For T84 intestinal epithelial cells important roles of CD11b/CD18, but also CD11b/CD18-independent mechanisms, have been described under specific inflammatory conditions $[31,41]$. Along these lines we observed that PMN transmigration through PCPECs is also CD11b/CD18-dependent. Interestingly, we found no evidence for a role of the integrin-associated glycoprotein CD47 during PMN migration through choroid plexus epithelium. In contrast, in intestinal epithelial cells CD47 plays an essential role in PMN transepithelial migration and in signalling events involving the signal regulatory protein $\alpha$ (SIRP $\alpha)$ [12]. Other potential binding partners of PMNs on the surfaces of PCPECs are ICAM- 1 for the $\beta_{2}$-integrins and VCAM- 1 for the $\beta_{1}$-integrins. In cultured intestinal epithelial monolayers ICAM-1 is not involved in PMN transmigration and is not a counter receptor for $\mathrm{CD} 11 \mathrm{~b} / \mathrm{CD} 18$ on the basolateral cell side of the cells [42]. Instead, CD11b/CD18 promotes adherence of PMNs at the apical cell surface and, rather, binding to fucosylated glycoproteins at the basolateral cell side $[43,44]$. In contrast, the transendothelial migration of most leukocytes has been shown to be ICAM-1-, VCAM1-, CD11a/CD18- and CD11b/CD18-dependent [15]. Ultrastructural studies in an experimental autoimmune encephalomyelitis model revealed polar localization of ICAM-1, VCAM-1, and MAdCAM-1 on the apical surface of choroid plexus epithelial cells and their complete absence on the fenestrated endothelial cells within the choroid plexus parenchyma [6].

Since contrary data exist about the role of ICAM-1 and VCAM-1 in PMN adhesion and transmigration as described above we were interested in their role on PCPECs after infection with S. suis. We analyzed mRNA levels for these adhesion molecules in PCPECs under bacterial infection with $S$. suis strain 10 and its isogenic mutant strain $10 \Delta \mathrm{cps}$ and after TNFa stimulation, using quantitative real time-PCR. The mRNA expressions of ICAM-1 and VCAM-1 were considerably upregulated with VCAM-1 to a greater extent than ICAM-1 and with TNF $\alpha$ as the strongest stimulus. ICAM-1 upregulation was significantly more enhanced after infection with S. suis strain $10 \Delta$ cps. Thus, we speculate that this effect may be due to the higher invasion capacity of this strain as recently demonstrated [4]. These data indicate a certain involvement of the adhesion molecules on PCPECs after S. suis infection. Further studies are necessary to determine the exact localization of these CAMs on PCPECs and their binding partners.

\section{Conclusion}

The present study gives new insights in PMN transepithelial migration and describes for the first time the transcellular pathway of PMNs through epithelial cells as the final step in diapedesis. Moreover, we were able to demonstrate mechanisms of PMN transmigration through the bloodCSF barrier after S. suis infection and TNF $\alpha$ stimulation in vitro, which could be relevant for therapeutic strategies in controlling neutrophilic inflammation.

\section{Acknowledgements}

This work was supported by grants from the Deutsche

Forschungsgemeinschaft (TE 653/2-1, SFB629 TPB2 and Graduiertenkolleg 1409). The authors wish to thank Dr. M. Vogel for helping with the artwork and chief technician M.L. Mölleken for expert advice. The help in electron microscopy by Dr. Heinz Schwarz and Gabi Frommer-Kästle is also gratefully acknowledged.

\section{Author details}

'Department of General Pediatrics, University Children's Hospital, HeinrichHeine-University, Düsseldorf, Germany. ${ }^{2}$ Institute for Genetics of Heart Diseases, Department of Cardiology and Angiology, University Hospital Münster, Germany. ${ }^{3}$ Institute of Pathology, University of Tuebingen,

Tuebingen, Germany. ${ }^{4}$ Institute of Infectiology, Centre for Molecular Biology of Inflammation (ZMBE), Westfälische Wilhelms-University, Münster, Germany. ${ }^{5}$ Max Planck Institute of Developmental Biology, Tuebingen, Germany. ${ }^{6}$ Department of Biochemistry, Westfälische Wilhelms-University, Münster, Germany. ${ }^{7}$ Pediatric Infectious Diseases, Department of Pediatrics, University Hospital Mannheim, Heidelberg University, Mannheim, Germany.

\section{Authors' contributions}

$\Pi T$ and CW conceived and coordinated the study, and drafted the manuscript. CW, AS, UQ performed transmigration, immunofluorescence, qReal Time-PCR and FACS experiments. HW, LG, MAS, JB, UQ performed the electron microscopic studies. HJG, CS, HS have co-conceived the study and have been involved in drafting the manuscript. All authors have read and approved the final version of this manuscript.

\section{Competing interests}

The authors declare that they have no competing interests.

Received: 15 January 2011 Accepted: 18 May 2011

Published: 18 May 2011

\section{References}

1. Zhang JR, Tuomanen E: Molecular and cellular mechanisms for microbial entry into the CNS. J Neurovirol 1999, 5:591-603. 
2. Kim KS: Pathogenesis of bacterial meningitis: from bacteraemia to neuronal injury. Nat Rev Neurosci 2003, 4:376-385.

3. Tenenbaum T, Matalon D, Adam R, Seibt A, Wewer C, Schwerk C, Galla HJ, Schroten $\mathrm{H}$ : Dexamethasone prevents alteration of tight junctionassociated proteins and barrier function in porcine choroid plexus epithelial cells after infection with Streptococcus suis in vitro. Brain Res 2008, 1229:1-17.

4. Tenenbaum T, Papandreou T, Gellrich D, Friedrichs U, Seibt A, Adam R, Wewer C, Galla HJ, Schwerk C, Schroten H: Polar bacterial invasion and translocation of Streptococcus suis across the blood-cerebrospinal fluid barrier in vitro. Cell Microbiol 2009, 11:323-336.

5. Strazielle N, Ghersi-Egea JF: Choroid plexus in the central nervous system: biology and physiopathology. J Neuropathol Exp Neurol 2000, 59:561-574.

6. Engelhardt B, Wolburg-Buchholz K, Wolburg H: Involvement of the choroid plexus in central nervous system inflammation. Microsc Res Tech 2001, 52:112-129.

7. Lun ZR, Wang QP, Chen XG, Li AX, Zhu XQ: Streptococcus suis: an emerging zoonotic pathogen. Lancet Infect Dis 2007, 7:201-209.

8. Williams AE, Blakemore WF: Pathogenesis of meningitis caused by Streptococcus suis type 2. J Infect Dis 1990, 162:474-481.

9. Madsen LW, Svensmark B, Elvestad K, Aalbaek B, Jensen HE: Streptococcus suis serotype 2 infection in pigs: new diagnostic and pathogenetic aspects. J Comp Pathol 2002, 126:57-65.

10. Dominguez-Punaro MC, Segura M, Plante MM, Lacouture S, Rivest S, Gottschalk M: Streptococcus suis serotype 2, an important swine and human pathogen, induces strong systemic and cerebral inflammatory responses in a mouse model of infection. J Immunol 2007, 179:1842-1854

11. Tenenbaum T, Adam R, Eggelnpohler I, Matalon D, Seibt A, GE KN, Galla HJ, Schroten $\mathrm{H}$ : Strain-dependent disruption of blood-cerebrospinal fluid barrier by Streptoccocus suis in vitro. FEMS Immunol Med Microbiol 2005, 44:25-34.

12. Chin AC, Parkos CA: Pathobiology of neutrophil transepithelial migration: implications in mediating epithelial injury. Annu Rev Pathol 2007, 2:111-143

13. Zemans RL, Colgan SP, Downey GP: Trans-Epithelial Migration of Neutrophils: Mechanisms and Implications for Acute Lung Injury. Am J Respir Cell Mol Biol 2008.

14. Ransohoff RM, Kivisakk P, Kidd G: Three or more routes for leukocyte migration into the central nervous system 2003, 3:569-581.

15. Engelhardt B, Wolburg H: Mini-review: Transendothelial migration of leukocytes: through the front door or around the side of the house? Eur J Immunol 2004, 34:2955-2963.

16. Ling EA, Kaur C, Lu J: Origin, nature, and some functional considerations of intraventricular macrophages, with special reference to the epiplexus cells. Microsc Res Tech 1998, 41:43-56.

17. Wolburg H, Wolburg-Buchholz K, Engelhardt B: Diapedesis of mononuclear cells across cerebral venules during experimental autoimmune encephalomyelitis leaves tight junctions intact. Acta Neuropathol 2005 109:181-190.

18. Phillipson M, Kaur J, Colarusso P, Ballantyne CM, Kubes P: Endothelial domes encapsulate adherent neutrophils and minimize increases in vascular permeability in paracellular and transcellular emigration. PLoS One 2008, 3:e1649.

19. Zen K, Parkos CA: Leukocyte-epithelial interactions. Curr Opin Cell Biol 2003, 15:557-564.

20. Worthylake RA, Burridge K: Leukocyte transendothelial migration: orchestrating the underlying molecular machinery. Current Opinion in Cell Biology 2001, 13:569-577.

21. Smith HE, Damman M, van der Velde J, Wagenaar F, Wisselink HJ, Stockhofe-Zurwieden N, Smits MA: Identification and characterization of the cps locus of Streptococcus suis serotype 2: the capsule protects against phagocytosis and is an important virulence factor. Infect Immun 1999, 67:1750-1756.

22. Gath U, Hakvoort A, Wegener J, Decker S, Galla HJ: Porcine choroid plexus cells in culture: expression of polarized phenotype, maintenance of barrier properties and apical secretion of CSF-components. Eur J Cell Biol 1997, 74:68-78.

23. Haverson K, Saalmüller A, Alvarez B, Alonso F, Bailey M, Bianchi AT, Boersma WJ, Chen Z, Davis WC, Dominguez J, Engelhardt H, Ezquerra A, Grosmaire LS, Hamilton MJ, Hollemweguer E, Huang CA, Khanna KV, Kuebart G, Lackovic G, Ledbetter JA, Lee R, Llanes D, Lunney JK,
McCullough KC, Molitor T, Nielsen J, Niewold TA, Pescovitz MD, de la Lastra JM, Rehakova Z, et al: Overview of the Third International Workshop on Swine Leukocyte Differentiation Antigens. Veterinary Immunology and Immunopathology 2001, 80:5-23.

24. Haverson K, Saalmüller A, Chen Z, Huang CA, Simon A, Seebach J, Boersma WJ, Zwart R, Niewold TA, Thacker E, Llanes D, de la Lastra JM, Engelhardt H, Ezquerra A, Alonso F, Dominguez J, Ledbetter JA Grosmaire L, Lee R, Nielsen J, Salmon H, Valpotic I, Sver L, Lackovic G, Summerfield A, Khanna KV: Summary of the first round analyses of the Third International Workshop on Swine Leukocyte Differentiation Antigens. Veterinary Immunology and Immunopathology 2001, 80:25-34.

25. Shahein YE, de Andres DF, Perez de la Lastra JM: Molecular cloning and functional characterization of the pig homologue of integrin-associated protein (IAP/CD47). Immunology 2002, 106:564-576.

26. Zeni P, Doepker E, Schulze-Topphoff U, Huewel S, Tenenbaum T, Galla HJ: MMPs contribute to TNF-alpha-induced alteration of the bloodcerebrospinal fluid barrier in vitro. Am J Physiol Cell Physiol 2007, 293: C855-864.

27. Wong D, Prameya R, Dorovini-Zis K: Adhesion and migration of polymorphonuclear leukocytes across human brain microvessel endothelial cells are differentially regulated by endothelial cell adhesion molecules and modulate monolayer permeability. I Neuroimmunol 2007, 184:136-148.

28. Rosenberg GA, Estrada EY, Dencoff JE, Stetler-Stevenson WG: Tumor necrosis factor-alpha-induced gelatinase $B$ causes delayed opening of the blood-brain barrier: an expanded therapeutic window. Brain Res 1995, 703:151-155.

29. Detmers PA, Lo SK, Olsen-Egbert E, Walz A, Baggiolini M, Cohn ZA: Neutrophil-activating protein 1/interleukin 8 stimulates the binding activity of the leukocyte adhesion receptor CD11b/CD18 on human neutrophils. J Exp Med 1990, 171:1155-1162.

30. Semple BD, Kossmann T, Morganti-Kossmann MC: Role of chemokines in CNS health and pathology: a focus on the CCL2/CCR2 and CXCL8/CXCR2 networks. J Cereb Blood Flow Metab 30:459-473.

31. Parkos CA, Delp C, Arnaout MA, Madara JL: Neutrophil migration across a cultured intestinal epithelium. Dependence on a CD11b/CD18-mediated event and enhanced efficiency in physiological direction. J Clin Invest 1991, 88:1605-1612.

32. Burns AR, Bowden RA, MacDonell SD, Walker DC, Odebunmi TO, Donnachie EM, Simon SI, Entman ML, Smith CW: Analysis of tight junctions during neutrophil transendothelial migration. J Cell Sci 2000, 113(Pt 1):45-57.

33. Edens HA, Levi BP, Jaye DL, Walsh $\mathrm{S}$, Reaves TA, Turner JR, Nusrat $A$, Parkos CA: Neutrophil transepithelial migration: evidence for sequential, contact-dependent signaling events and enhanced paracellular permeability independent of transjunctional migration. J Immunol 2002, 169:476-486.

34. Wittchen ES: Endothelial signaling in paracellular and transcellular leukocyte transmigration. Frontiers in Bioscience 2009, 14:2522-2545.

35. Balda MS, Matter K: Tight junctions at a glance. J Cell Sci 2008, 121:3677-3682

36. Joannidis M, Truebsbach S, Bijuklic K, Schratzberger P, Dunzedorfer $S$, Wintersteiger S, Lhotta K, Mayer G, Wiedermann CJ: Neutrophil transmigration in renal proximal tubular LLC-PK1 cells. Cell Physio Biochem 2004, 14:101-112.

37. Chabot-Roy G, Willson P, Segura M, Lacouture S, Gottschalk M: Phagocytosis and killing of Streptococcus suis by porcine neutrophils. Microb Pathog 2006, 41:21-32.

38. von Wedel-Parlow M, Schrot S, Lemmen J, Treeratanapiboon L, Wegener J, Galla HJ: Neutrophils cross the BBB primarily on transcellular pathways: an in vitro study. Brain Res 2011, 1367:62-76.

39. Szmydynger-Chodobska J, Strazielle N, Zink BJ, Ghersi-Egea JF, Chodobski A: The role of the choroid plexus in neutrophil invasion after traumatic brain injury. J Cereb Blood Flow Metab 2009, 29:1503-1516.

40. Phillipson M, Heit B, Colarusso P, Liu L, Ballantyne CM, Kubes P: Intraluminal crawling of neutrophils to emigration sites: a molecularly distinct process from adhesion in the recruitment cascade. J Exp Med 2006, 203:2569-2575

41. Blake KM, Carrigan SO, Issekutz AC, Stadnyk AW: Neutrophils migrate across intestinal epithelium using beta2 integrin (CD11b/CD18)independent mechanisms. Clin Exp Immunol 2004, 136:262-268. 
42. Colgan SP, Parkos CA, Delp C, Arnaout MA, Madara JL: Neutrophil migration across cultured intestinal epithelial monolayers is modulated by epithelial exposure to IFN-gamma in a highly polarized fashion. I Cell Biol 1993, 120:785-798.

43. Colgan SP, Parkos CA, McGuirk D, Brady HR, Papayianni AA, Frendl G, Madara JL: Receptors involved in carbohydrate binding modulate intestinal epithelial-neutrophil interactions. J Biol Chem 1995, 270:10531-10539.

44. Parkos CA, Colgan SP, Diamond MS, Nusrat A, Liang TW, Springer TA, Madara JL: Expression and polarization of intercellular adhesion molecule-1 on human intestinal epithelia: consequences for CD11b/ CD18-mediated interactions with neutrophils. Mol Med 1996, 2:489-505.

doi:10.1186/1742-2094-8-51

Cite this article as: Wewer et al: Transcellular migration of neutrophil granulocytes through the blood-cerebrospinal fluid barrier after infection with Streptococcus suis. Journal of Neuroinflammation 2011 8:51.

\section{Submit your next manuscript to BioMed Central} and take full advantage of:

- Convenient online submission

- Thorough peer review

- No space constraints or color figure charges

- Immediate publication on acceptance

- Inclusion in PubMed, CAS, Scopus and Google Scholar

- Research which is freely available for redistribution

Submit your manuscript at www.biomedcentral.com/submit 